\title{
The synthesis of bottom-up and top-down approaches to climate policy modeling: Electric power technologies and the cost of limiting US $\mathrm{CO}_{2}$ emissions th $^{2}$
}

\author{
Ian Sue Wing ${ }^{\mathrm{a}, \mathrm{b}, \mathrm{c}, *}$ \\ ${ }^{a}$ Kennedy School of Government, Harvard University, USA \\ ${ }^{\mathrm{b}}$ Center for Energy \& Environmental Studies and Department of Geography \& Environment, Boston University, Rm. 141, \\ 675 Commonwealth Ave., Boston, MA 02215, USA \\ ${ }^{\mathrm{c}}$ Joint Program on the Science \& Policy of Global Change, MIT, USA
}

Available online 19 October 2005

\begin{abstract}
In the US, the bulk of $\mathrm{CO}_{2}$ abatement induced by carbon taxes comes from electric power. This paper incorporates technology detail into the electricity sector of a computable general equilibrium model of the US economy to characterize electric power's technological margins of adjustment to carbon taxes and to elucidate their general equilibrium effects. Compared to the top-down production function representation of the electricity sector, the technology-rich hybrid specification produces less abatement at a higher welfare cost, suggesting that bottom-up models do not necessarily generate lower costs of abatement than top-down models. This result is shown to be sensitive to the elasticity with which technologies' generating capacities adjust to relative prices.
\end{abstract}

(C) 2005 Elsevier Ltd. All rights reserved.

JEL Classification: C680; Q400; Q540

Keywords: Energy modeling; Climate change; Computable general equilibrium models

\section{Introduction}

Computable general equilibrium (CGE) analyses of the impacts of carbon taxes on the US economy suggest that the largest reductions of emissions of carbon dioxide $\left(\mathrm{CO}_{2}\right)$ will come from the electric power sector (Sue Wing, 2004a). This paper incorporates electricity technology detail into a CGE model for the US to identify the electric power

This research was supported by US Department of Energy Office of Science (BER) Grant no. DE-FG02-02ER63484. Dan Basoli provided expert research assistance. The paper has benefited from helpful comments by seminar participants at Dartmouth College, the 11th Annual Conference on Computing in Economics and Finance, and an anonymous referee. Errors and omissions remain the sole responsibility of the author.

* Center for Energy \& Environmental Studies and Department of Geography \& Environment, Boston University, Rm. 141, 675 Commonwealth Ave., Boston, MA 02215, USA. Tel.: + 16173535741 ; fax: +16173535986 .

E-mail address: isw@bu.edu. sector's margins of technological adjustment to taxes on $\mathrm{CO}_{2}$ emissions, and impacts of these margins on aggregate economic variables. The simulation results demonstrate that the malleability of capacity is an important determinant of energy technological substitution and is a key driver of the costs of policies to mitigate climate change. As compared to the usual top-down macroeconomic representations of sectors as smooth nested production functions, the inclusion of bottom-up engineering details of discrete technologies in those sectors responsible for the bulk of $\mathrm{CO}_{2}$ abatement results in higher welfare losses. The results emphasize the importance of short-run capacity adjustment as a determinant of the macroeconomic costs of climate policy.

Computational simulations for assessing the costs of policies to mitigate anthropogenic emissions of greenhouse gases (GHGs) typically fall into two categories: bottom-up models, which simulate the interactions among the technologies that make up the economy's energy system, 
and top-down models, which simulate the market interactions among energy consumers, energy supply sectors and other industries in the economy.

It is useful at the outset to clarify how the terms bottomup and top-down will be used in the paper. Bottom-up models (e.g., MARKAL-Loulou et al., 2004) refer to primal activity analysis simulations that solve for the levels of capacity of energy transformation and conversion technologies that minimize the cost of fulfilling demands for energy services that are either specified according to demand curves or derived from a simple aggregate macroeconomic model (e.g. Manne et al., 1995). They contain a detailed description of the energy system in the form of a technology matrix that represents the level of capacity of individual processes for transforming different primary energy resources into a range of energy carriers, and for converting these commodities into energy services that satisfy final demands.

Top-down models refer to macroeconomic simulations which come in two flavors: primal aggregate Ramsey growth models with an environmental sector (e.g., DICE and RICE-Nordhaus and Boyer, 1999), and primal-dual CGE models (e.g., EPPA-Paltsev et al., 2005) that solve for the set of commodity and factor prices, and the levels of industry activity and household income that clear all markets in the economy, given aggregate factor endowments, households' consumption technologies (specified by their utility functions) and industries' transformation technologies (specified by their production functions). This focus of this paper is on the latter category, CGE models.

Although the analytical contributions of these two approaches are complementary, their results have tended to diverge, with top-down models typically indicating larger macroeconomic costs as the consequence of a given mitigation policy (National Academy of Sciences (NAS), 1991, p. 62; Grubb et al., 1993; Wilson and Swisher, 1993; IPCC, 1995, 2005). The origins of this divide are by now well understood, with perhaps the biggest factor being bottom-up models' technological optimism about low-cost abatement potentials. ${ }^{1}$ Nevertheless, what remains unclear is how, for a given degree of technological optimism, the behavior of top-down models will tend to respond to the inclusion of more realistic specifications of individual energy technologies. The contribution of present paper is to improve our understanding of this issue.

Methodologically, the paper has its roots a new class of simulations - the so-called "hybrid" models - which bridges the bottom-up/top-down divide by integrating the detailed representation of energy technologies found in bottom-up models into CGE models' equilibrium structure

\footnotetext{
${ }^{1}$ The major differences between top-down and bottom-up models lie in their domains (economy-wide versus the energy system), solution concept (primal partial equilibrium versus primal-dual general equilibrium), scope for substitution (the demand influences of non-energy sectors and the supply influences of factor price changes versus discrete technology set), and inclusion of optimistic low- or negative-cost emission reduction possibilities (IPCC, 2001).
}

(Boehringer, 1998; Boehringer et al., 2003; Frei et al., 2003; Kumbaroglu and Madlener, 2003; McFarland et al., 2004). Like these studies, this paper focuses on electric power, developing a hybrid CGE model of the US economy in which the electricity sector is disaggregated into numerous discrete generation technologies.

Unlike previous work, this paper emphasizes the challenges which attend the introduction of a detailed description of the technology frontier into a general equilibrium framework, and the implications of strategies to address them. The key issue is the so-called "flip flop" problem, whereby small changes in technologies' unit costs give rise to implausibly large changes in their activity levels and market shares. Such behavior is an undesirable feature in static models in which discrete technologies are perfect substitutes, and in forward-looking models with an activity-analysis representation of production in which producers' inter-temporal adjustments of technology-specific capital stocks are fundamentally linked to their intratemporal capacity utilization decisions. Mitigating this pathology requires careful attention to the specification of competition among technologies on one hand, and the adjustment process of technology-specific capital on the other. A further issue is the numerical calibration of the resulting bottom-up/top-down structure, which requires a solution to the thorny problem of reconciling incommensurate data on the electricity sector's demands for inputs, statistics on the distribution of generation by technology, and engineering estimates of the latter's unit input requirements.

The hybrid model serves as the test-bed for investigating the effects of $\mathrm{CO}_{2}$ emission taxes. The simulation results elucidate the changes in the electricity generation technology portfolio which are likely to be induced by climate policies, and demonstrate the consequences for aggregate economic welfare. A second novel aspect of the paper is that undertakes a forensic comparison of the impacts of carbon taxes in the hybrid model and an otherwiseidentical top-down model built entirely using smooth production functions. Doing so gives new insight into the relative importance for climate policy costs of the discretization of the technology set and the imperfect malleability of technology-specific capital.

The caveat is that realistic emission reduction policies are not analyzed. Rather than attempt to evaluate actual $\mathrm{CO}_{2}$ abatement proposals (e.g., National Commission on Energy Policy (NCEP), 2004), the paper opts for the simpler approach of examining the effects of stylized policies in today's economy, employing available statistics as a known, constant benchmark. By contrast, analyzing realistic policies requires the projection of baseline activity levels for myriad electricity generation technologies over the coming decades, which involves the additional assumptions and the introduction of considerable uncertainty. These complications are avoided through the use of a static equilibrium approach, which facilitates clearer illustration of the character and implications of the technological 
adjustments likely to be induced by climate policies over a 5-10 years period.

The paper's main result is that welfare costs of abatement policies are higher in the hybrid model than in the top-down model with conventional production functions. This outcome can be traced to the fact that the specification of generation technologies as fixed-coefficient activities makes the electric sector's production function less smooth in the hybrid model compared to its top-down counterpart, reducing the aggregate input substitutability on the supply side of the economy. More importantly, in the hybrid model, the imperfect malleability of technologyspecific capital within electricity sector limits the adjustment of generating capacity in the short-run, substantially increasing the distortionary effects of emission taxes. This last factor has received scant attention in either top-down or bottom-up studies, and is ripe for investigation.

The remainder of the paper is divided into five sections. Section 2 describes the general equilibrium framework which is common to the hybrid and the top-down models. Section 3 outlines the structure and implications of the different ways of representing the electricity sector in each model: a smooth nested production function in the topdown model, and a disaggregation of the sector into discrete generation technologies reminiscent of bottom-up energy system detail in the hybrid model. Section 4 describes the data and parameters used to calibrate each simulation. Section 5 reports and discusses the results of computational experiments in which the models are used to simulate the effects of carbon taxes at different levels. Section 6 provides a summary and concluding remarks.

\section{The structure of the CGE model}

The numerical experiments in the paper require the simulation of two models: a top-down model in which every sector is represented by a smooth production function, and a hybrid model in which the electric power sector is represented by an array of discrete technologies. This section describes the general equilibrium framework at the core of both models.

The hybrid and the top-down model are each based on the same static CGE simulation of the US economy. ${ }^{2}$ The supply side of the economy is divided into 11 industries (denoted $N$ and indexed by $j=\{1, \ldots, N\}$ ), each of which is modeled as representative firms that produces a single commodity. These goods (indexed by $j=\{1, \ldots, N\}$ ) are of two types, energy goods (coal, oil, natural gas and electricity: $e \subset N)$ and non-energy goods $(m \subset N)$. Households are collectively modeled as a representative agent who is endowed with three factors of production, labor $(L)$, capital $(K)$ and industry-specific natural resources $(R)$,

\footnotetext{
${ }^{2}$ The general equilibrium framework is specified according to the openeconomy format of Harrison et al. (1997). The representation of international trade has negligible influence on the results, and does not merit further discussion.
}
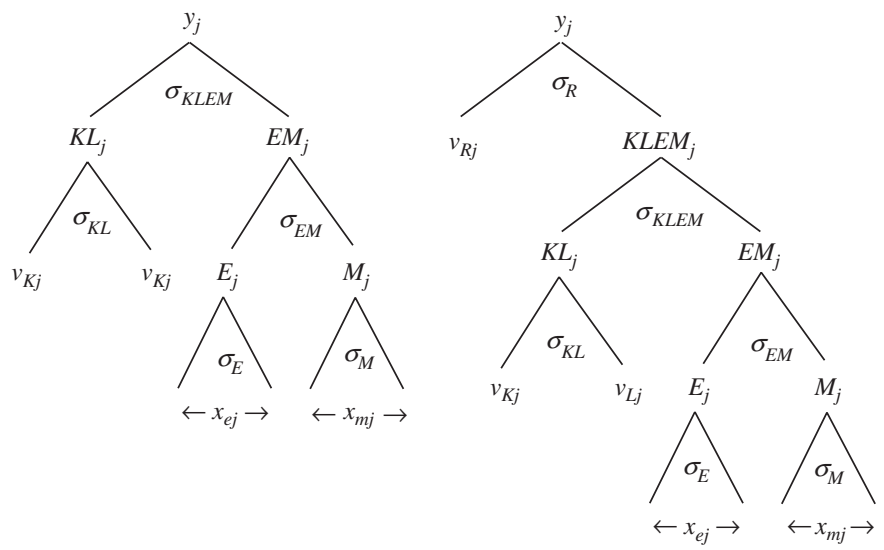

(A) Non-Primary Sectors

(B) Primary (Resource) Sectors

Fig. 1. The structure of production in the non-electric sectors: (A) nonprimary sectors; and (B) primary (resource) sectors.

indexed by $f=\{L, K, R\}$. The government is modeled as a passive entity which demands commodities and transforms them into a government good, which in turn is demanded by the representative agent.

The model treats the households' aggregate capital endowment as fixed, but specifies their endowments of labor and natural resources as increasing functions of the wage and prices of domestic output in resource-using industries, respectively, governed by elasticities of labor and fixed-factor supply (denoted $\eta_{L}$ and $\eta_{R j}$ ). Income from the rental of these factors to the firms in the economy finances the households' use of commodities for consumption and investment. The aggregate investment and government commodities are produced according to Cobb-Douglas transformation functions of the goods in the economy. Aggregate investment is linked to the aggregate rate of return on capital through an investment demand function which maintains the economy on its initial growth path.

The representative agent's preferences are modeled according to a constant elasticity of substitution (CES) utility function. ${ }^{3}$ Industries generate output $(y)$ by combining inputs of primary factors $(v)$ and intermediate uses of commodities $(x)$ according to multi-level CES production functions modeled after Bovenberg and Goulder (1996). Their structure is shown schematically in Fig. 1, where each node of the tree in the diagram represents the output of an individual CES function, and the branches represent its inputs, whose fungibility at each level of the nesting structure is determined by the corresponding substitution elasticities: $\sigma_{K L E M}, \sigma_{K L}, \sigma_{E M}, \sigma_{E}, \sigma_{M}$ and $\sigma_{R}$.

Thus, for the non-resource sectors in panel A, output $\left(y_{j}\right)$ is a CES function of a composite of labor and capital inputs $\left(K L_{j}\right)$ and a composite of energy and material inputs $\left(E M_{j}\right) . K L_{j}$ represents the value added by primary factors' contribution to production, and is a CES function of inputs

\footnotetext{
${ }^{3}$ The numeraire in the model is the price index of "utility", which is the CES composite of households' consumption of commodities.
} 
of labor, $v_{L j}$, and capital, $v_{K j}$. $E M_{j}$ represents the value of intermediate inputs' contribution to production, and is a CES function of two further composites: $E_{j}$, which is itself a CES function of energy inputs, $x_{e j}$, and $M_{j}$, which is a CES function of non-energy material inputs, $x_{m j}$.

Panel B shows the structure of production in resourcebased sectors. Because natural resource inputs play a central role here, they are modeled as a sector-specific fixed factor which enters at the top level of the production hierarchy. Output is thus a CES function of the resource input, $v_{R j}$, and the composite of the inputs of capital, labor, energy and materials $\left(K L E M_{j}\right)$.

Profit maximization by industries and utility maximization by the representative agent result in vectors of demands for commodities and factors, which are functions of goods and factor prices, industries' activity levels and the income level of the representative agent. The CGE model is specified in a complementarity format, in which the general equilibrium of the economy is posed as a vector of market clearance, zero-profit and income balance equations (Scarf, 1973; Mathiesen, 1985a, b; Rutherford, 1987).

The model's algebraic structure results from substituting the demand functions into these equilibrium conditions to yield a square system of nonlinear inequalities which defines the aggregate excess demand correspondence of the economy (Sue Wing, 2004a). The excess demand correspondence is formulated as a mixed complementarity problem (MCP), numerically calibrated using the MPSGE subsystem for GAMS (Rutherford, 1999; Brooke et al., 1998), and solved using the PATH solver (Dirkse and Ferris, 1995). Details of the model parameters and calibration are given in Section 4 below.

\section{Modeling the electricity sector: bottom-up vs. top-down approaches}

This section describes the bottom-up and top-down representations the electric power sector which are integrated into the general equilibrium framework of Section 2 to yield the hybrid and the top-down models, respectively. The top-down approach employs a smooth nested production function similar to those employed in Fig. 1, while the hybrid model specifies the sector as an array of discrete technologies. Comparability of the results of the two models is maximized by ensuring that the differences between them are confined to the electric power sector, with the remainder of the economy being specified as in Section 2.

\subsection{The top-down model}

From a macro-perspective, the generation of electric power is adequately described by production functions like those in the previous section. However, to facilitate accurate accounting for energy and carbon emissions, electricity production from fossil fuels and nuclear and renewables should be sufficiently resolved at the sub-sector level that their outputs and inputs can be separately identified. The implication of this requirement is that the production function for electric power should reflect the characteristics of both the resource-using and non-resource using industries in Fig. 1.

Accordingly, the electricity sector in the top-down model is specified as the amalgam of these two structures, as illustrated in panel A of Fig. 2. Conventional fossil electricity generation $(F)$ is represented by the production structure in Fig. 1A, combining labor, capital and materials with inputs of coal, oil and natural gas. Nonfossil generation (i.e., nuclear and renewables, $N F$ ) relies ultimately on primary energy resources, and is represented by the production structure in Fig. 1B, minus the inputs of fossil fuels, and combines labor, capital and intermediate materials with $v_{N F}$, which represents a composite of nonfossil energy resources such as uranium deposits, wind and water flows, and hydrostatic head.

Total electricity output is modeled a CES function of the outputs of the $F$ and $N F$ sub-sectors. The elasticity of substitution between $y_{F}$ and $y_{N F}$ is $\sigma_{F-N F} \gg 1$, reflecting the fact that they are highly substitutable. Underlying this structural assumption are two diametrically opposing views of production. On one hand, electricity is a homogeneous commodity, with a kilowatt-hour ( $\mathrm{kW} \mathrm{h}$ ) of electricity from fossil fuels being identical to a $\mathrm{kWh}$ generated from nonfossil sources. The implication is that $\sigma_{F-N F}=\infty$. But on the other hand, it is a fact that fossil and non-fossil

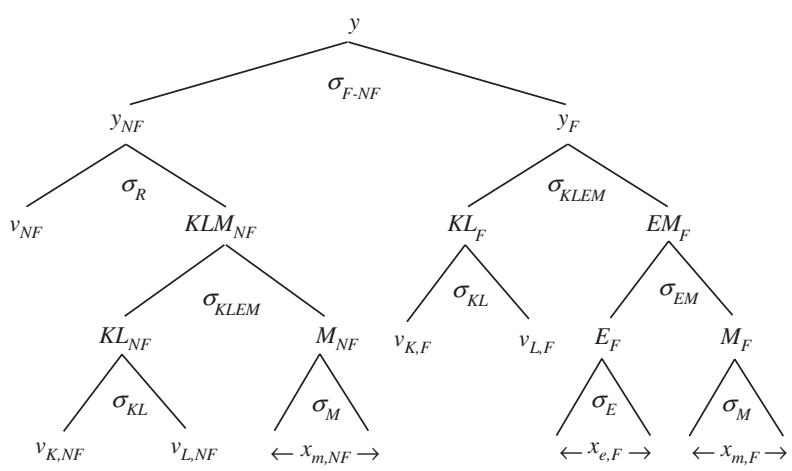

(A)

Top-Down Model

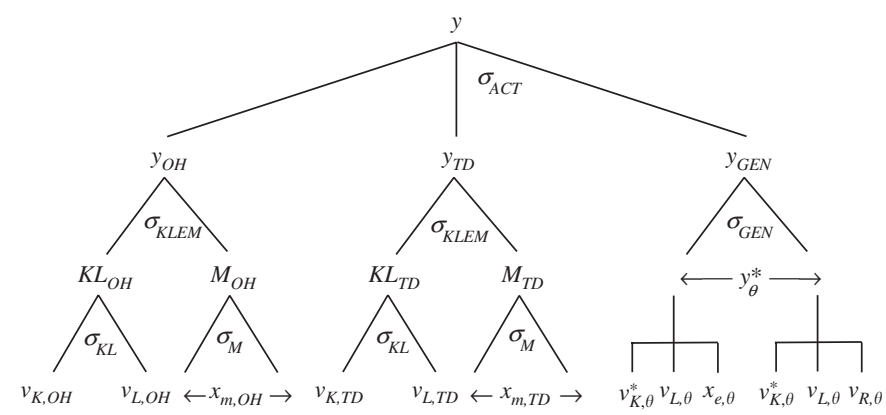

(B) Hybrid Model, Showing Bottom-Up technology Detail

Fig. 2. The structure of production in the electric power sector: (A) topdown model; and (B) hybrid model, showing bottom-up technology detail. 
generation coexists in electricity markets while producing at different marginal costs. This can only occur in the presence of differentiated demands, which implies that $\sigma_{F-N F}<\infty$. The tension between these perspectives is even more important in the hybrid model, as is elaborated below.

\subsection{The hybrid model: bottom-up technology detail in a top- down framework}

From a bottom-up perspective, the foregoing is a simplistic characterization of the way in which electric power production is actually organized. In the engineering view, electricity output is generated from a number of discrete technologies, each with its own distinct characteristics. This description corresponds to the traditional activity analysis model of production (e.g., as in Boehringer, 1998). In addition, the inputs to and the output of the electric power industry tabulated in the macroeconomic accounts are aggregations of the inputs to and the outputs of three distinct and complementary activities: electricity generation $(G E N)$, transmission and distribution $(T D)$, and the overhead $(\mathrm{OH})$ involved in administering the first two activities. $T D$ and $O H$ can be thought of as ancillary activities which do not consume inputs of primary energy. $G E N$ is a composite of individual generation technologies, which compete with each other on the output side to produce the lowest-cost electricity, and on the input side for primary factors and fuel.

In the hybrid model the production structure which is employed to capture these features is shown in panel B of Fig. 2. At the top level, the output of the sector is a CES aggregation of the three activities, indexed by $a c t=\{O H$, $T D, G E N\}$. These outputs of the latter are almost complementary, so that the elasticity of substitution among them is low: $\sigma_{A C T} \ll 1 .^{4} T D$ and $O H$ are modeled using nested CES production functions which combine inputs of labor and capital with non-energy intermediate materials to produce their outputs.

The generation activity is the CES aggregation of a vector of discrete generation technologies, indexed by $\theta$, each of which produces electricity $y_{\theta}^{*}$. Each technology is as a fixed-coefficients (Leontief) production function of labor, capital, and either an individual fossil fuel or the electricity sector's natural resource. The input of capital to each technology, indicated by $v_{K, \theta}^{*}$, can be thought of as a fixed factor which is separate from intersectorally mobile "malleable" capital, $v_{K}$. The main consequence of the Leontief specification of production is that the supply of $v_{K, \theta}^{*}$ determines the upper bound on the output of technology $\theta$. Thus, the endowment of each type of technology-specific capital is equivalent to the capacity

\footnotetext{
${ }^{4}$ For example, increases in the supply of maintenance labor or transmission capital can raise the output of $T D$, thereby increasing the quantity of electricity delivered to consumers for a given level of generation.
}

of the corresponding category of generation and its price (say $p_{K, \theta}^{*}$ ) can be interpreted as the dual capacity rent, distinct from the rental rate on malleable capital.

An important feature of the hybrid model is its ability to represent the kinds of capacity adjustments which electric power producers are likely to undertake over the 5- to 10year-time frame that characterizes an individual period in integrated assessment simulations. Fixed technology-specific capital endowments imply that some types of generation may be operated below capacity, in which case $p_{K, \theta}^{*}$ will tend to zero. However, if endowments can adjust, the supply-demand balance for $v_{K, \theta}^{*}$ will ensure that capacity remains fully utilized as prices change, consistent with the assumptions of full employment and no free disposability which underlie most CGE models. In this situation, a decline in $v_{K, \theta}^{*}$ and $p_{K, \theta}^{*}$ represents capacity scrapping or retirement while an increase indicates capacity addition or retrofit.

The trick used to adjust the endowments of technologyspecific capital is to model $v_{K, \theta}^{*}$ as partially reversible, with retirement being the transformation of existing capacity into malleable capital, and retrofit being the transformation of malleable capital into additional capacity. This is made operational through the device of a dummy "capacity transformation" sub-sector, specified as a constant elasticity of transformation (CET) function which demands intersectorally mobile capital and transforms it into the various categories of technology-specific capital. ${ }^{5}$

The critical parameter governing the malleability of capacity is the elasticity of transformation associated with this sub-sector, $\sigma_{C A P}$. The lower the value of this parameter the greater the degree of "sunk-ness" or irreversibility in electricity generation, in the sense that technology-specific capital is limited in its ability to be re-allocated to more productive uses as prices change. While there are empirical estimates of the effects of prices on capital retirement (Goolsbee, 1993, 1998) or the shape of industries' adjustment costs (Goolsbee and Gross, 1997), none of these can be used to derive a value for $\sigma_{C A P}$. In the absence of empirical evidence, this parameter is assigned a base-case value of unity, which generates plausible results. Sensitivity analyses are conducted to test the effect of this assumption on the hybrid model's response to carbon taxes at different levels.

\subsection{Challenges of hybrid modeling}

The challenges in constructing the hybrid model stem from the need to represent the static (intra-temporal) and dynamic (inter-temporal) aspects of technology substitution.

Focusing first on the intra-temporal dimension, the homogeneity of electric power as a commodity belies the

\footnotetext{
${ }^{5}$ The effect of capital immobility on the responses of CGE models to policy shocks has been studied by Fullerton (1983) and Jacoby and Sue Wing (1999).
} 
considerable variation in the characteristics of the technologies employed in its generation, as was noted above. The merit order of a base load coal or nuclear unit, a gas-fired peaking plant or a wind turbine differ substantially, reflecting these technologies' disparate availability factors and fuel and capital costs per $\mathrm{kWh}$. Moreover, they will typically produce output for different segments of the loadduration curve, implying that multiple types of generation with different marginal costs are simultaneously dispatched.

Capturing this phenomenon is the first major challenge in constructing hybrid models. In Fig. 2B, modeling technologies' outputs as perfect substitutes $\left(\sigma_{G E N}=\infty\right)$ results in the well-known "flip-flop" problem, whereby small shifts in the prices of fuel or other inputs to generation precipitate large changes in the shares of output produced by each technology. ${ }^{6}$ The structure of production must therefore be specified in a way that strikes a balance between the homogeneity of the $y_{\theta}^{*}$ 's on the one hand, and their imperfect substitutability with respect to different segments of the load-duration curve on the other. The CES formulation is a convenient method of aggregating technologies' outputs because it allows their marginal costs to differ while ensuring that their activity levels are positive. Moreover, the CES function tends to be stable - its homothetic, share preserving character implies that price changes will tend not to induce extreme deviations of technologies' market shares from their benchmark values, even with large elasticities of substitution. Accordingly, large baseline value for the generation elasticity was specified in the hybrid model $\left(\sigma_{G E N}=10\right)$ so as not to unduly constrain technology substitution.

But the CES function is not without drawbacks. It complicates the process of accounting for the output of the electric power sector and downstream electricity use in $\mathrm{kWh}$, because it aggregates economic quantities in a nonlinear fashion, conserving value but not physical energy flows. Looking again at Fig. 2B, at the hybrid model's calibration point where all prices and activity levels set to unity, the product of GEN's activity level and the total $\mathrm{kWh}$ of benchmark electricity generation is equal to the sum over technologies of the products of generators' activity levels and the benchmark $\mathrm{kWh}$ they produce. This equality ceases to hold at non-benchmark prices, with the result that the activity level $G E N$ can no longer be expressed as the sum of the levels of activity of its generation inputs, a problem which is further complicated by the aggregation of the output of $G E N$ with the nonenergetic outputs of the $O H$ and $T D$ activities. The general lesson is that in hybrid models energy accounting must be performed at the level of individual energy supply technologies, and the energetic coefficient on the output

\footnotetext{
${ }^{6}$ Grubler et al. (1999) give a frank account of the consequences of and remedies for this pathology in bottom-up simulations.
}

of the technology-rich sector varies endogenously with changes in prices.

By comparison, the challenge of representing the intertemporal dimension of technology substitution is far greater, as it necessitates modeling the process by which producers adjust stocks of technology-specific capital. The most theoretically correct specification of capacity adjustment is found in dynamic general equilibrium simulations based on the Kuhn-Tucker conditions of the standard Hayashi-Summers profit maximization problem of a forward-looking producer (e.g., Frei et al., 2003).

Computational implementation of such models is fraught with difficulty. Data on investment in energy supply technologies is rarely available, necessitating strategies such as balanced growth path calibration which force technologies' market shares to remain constant over models' baseline trajectories. But the thorniest issue is how to represent the process by which producers re-allocate investment among technologies as prices change. Even in full-employment dynamic models with multiple capital stocks, the inclusion of adjustment costs may not be adequate to prevent corner solutions in which investment is concentrated in only in one or two technologies. Furthermore, such pathological behavior is exacerbated by the fact that the activity analysis specification of production makes the Hayashi-Summers problem discontinuous, with the result that for a given technology, the relevant equations of motion are only active once output bumps up against the limit of extant capacity. ${ }^{8}$ Thus, it is likely that investment

\footnotetext{
${ }^{7} \mathrm{~A}$ little algebra illustrates this point. Let the energetic coefficient on the benchmark economic quantity of generation by technology be $\varepsilon_{\theta}^{0} \mathrm{kWh}$ per dollar. Numerical calibration of the sector so that all prices are unity implies that the benchmark economic quantity of total generation must equal the sum of the benchmark quantities of technologies' outputs, $G E N^{0}=\sum_{\theta} y_{\theta}^{0}$. Conservation of energy implies that benchmark total electricity generation is $\varepsilon_{G E N}^{0} G E N^{0}=\sum_{\theta} \varepsilon_{\theta}^{0} y_{\theta}^{0}$, where $\varepsilon_{G E N}^{0}$ (also in $\mathrm{kWh}$ per dollar) is the ratio of the sums of electricity production by technology in energetic and economic units. Because of the non-linearity of the CES aggregator, $G E N=C E S\left(y_{1}, \ldots, y_{\theta}\right)$ implies that at non-benchmark prices, $\varepsilon_{G E N}^{0} G E N \neq \sum_{\theta} \varepsilon_{\theta}^{0} y_{\theta}$. The energy coefficient on aggregate generation output is therefore endogenous: $\varepsilon_{G E N}=\sum_{\theta} \varepsilon_{\theta}^{0} y_{\theta} / G E N$, and will adjust as prices change. Note that this problem plagues the top-down structure in Fig. $2 \mathrm{~A}$ as well. In the notation of that model, the $\mathrm{kWh}$ per dollar of output of the electricity sector is given by $\varepsilon_{E L E C}=\left(\varepsilon_{F}^{0} F+\varepsilon_{N F}^{0} N F\right) / y$.

${ }^{8}$ Using $t$ to denote time, the key variables in the Hayashi-Summers model are the current capacity $\left(K_{t, \theta}^{*}\right)$, capacity rent $\left(P K_{t, \theta}^{*}\right)$, investment $\left(I_{t, \theta}^{*}\right)$ and gross capital return $\left(R K_{t, \theta}^{*}\right)$ for technology $\theta$. With full capacity utilization, the Kuhn-Tucker conditions imply the following equations and associated dual variables (where complementarity is denoted by “ $\perp$ "): an intertemporal market clearance condition for capital stocks given by the standard perpetual inventory equation with $\delta$ as the depreciation rate:

$K_{t+1, \theta}^{*}=I_{t, \theta}^{*}+(1-\delta) K_{t, \theta}^{*} \perp P K_{t, \theta}^{*} ;$

intertemporal zero profit condition for capital stocks given by the standard user cost equation, in which $\psi_{t, \theta}^{K}$ is the marginal adjustment cost of capacity:

$P K_{t, \theta}^{*}=R K_{t, \theta}^{*}-\psi_{t, \theta}^{K}+(1-\delta) P K_{t+1, \theta}^{*} \perp K_{t, \theta}^{*} ;$

an intratemporal market clearance condition for capital input, where the derivative in parentheses indicates the marginal productivity of
} 
will suffer from flip-flop behavior as well, to the detriment of model stability.

The ad hoc specification of capacity adjustment in Section 3.2 seeks to circumvent these difficulties by collapsing the essence of producers' capacity adjustment behavior into a static equilibrium framework. The basis for the approach is the fundamental relationship between intra-temporal capacity utilization decisions and intertemporal investment decisions outlined in footnote 4 . The practical implication of this linkage is that in a static framework even if generators' outputs are modeled as perfect substitutes, the potential for flip-flop behavior is still regulated by the ability of producers to adjust technology-specific capital. Previous hybrid modeling studies have largely overlooked this point.

To appreciate the importance of capacity malleability, consider that in MARKAL-type bottom-up simulations the levels of capacity in energy supply technologies are the key control variable. These models treat the supply of capacity as perfectly elastic but constrain adjustment through the use of bounds on technologies' maximum rates of expansion and decline, which are tuned according to modelers' sense of plausibility. By contrast, both static and dynamic hybrid CGE models tend to model technology-specific capital as being in perfectly inelastic supply within a given period.

Blurring the distinction between inter- and intratemporal adjustment is useful because elastic and inelastic capacity supply can then be thought of as the extremes of a continuum in which capacity exhibits varying degrees of responsiveness to price changes. It seems reasonable to assume that over a decadal time-period reality will lie somewhere in the middle, with climate policies inducing shifts in the relative marginal costs of generation to the point where producers find it economical to scrap and/or retrofit existing capital, resulting in the retirement of capacity in carbon-intensive technologies and capacity expansion in carbon-free technologies. But despite recent attempts to understand how inter-fuel substitution possibilities are mediated by capacity change in energy supply technologies (e.g., Vögele et al., 2004), the central unknown remains the short-run elasticity of adjustment of technology-specific capital to changes in energy prices.

(footnote continued)

capacity:

$R K_{t, \theta}^{*} K_{t, \theta}^{*}=y_{t, \theta}^{*}\left(\partial \Phi_{\theta}\left(K_{\theta}^{*}\right) / \partial K_{t, \theta}^{*}\right) \perp R K_{t, \theta}^{*} ;$

and zero profit for investment, where $\psi_{t, \theta}^{I}$ is the marginal adjustment cost of investment:

$P K_{t+1, \theta}=\psi_{t, \theta}^{I} \perp I_{t, \theta}$.

If the production function $\Phi_{\theta}$ is Leontief then the last three equations are discontinuous, with investment occurring only in those periods when capacity is a binding constraint on output. Otherwise $I_{t, \theta}^{*}, R K_{t, \theta}^{*}$ and $\partial \Phi_{\theta} / \partial K_{t, \theta}^{*}$ do not exist, a phenomenon which creates considerable numerical instability. The large fluctuations in capacity additions in Frei et al (2003, Fig. 6) and Kumbaroglu and Madlener (2003, Figs. 2 and 3) are symptomatic of the problem.
To fix ideas, consider the implications of the extrema discussed above in the short run. Treating $v_{K, \theta}^{*}$ as priceinvariant (i.e., $\sigma_{C A P}=0$ in Fig. $2 \mathrm{~B}$ ) requires each kind of technology-specific capital to be specified as a factor whose supply is fixed at the levels of the representative agent's benchmark endowments. Because capacity is fixed, utilization rates are the sole margin of adjustment for electricity generators. In this situation it is likely that carbon taxes will induce drastic reductions in the utilization of coal-fired electric generation at the same time as capacity constraints prevent the expansion of gas, nuclear or renewable generation, resulting in high macroeconomic costs.

Conversely, if $v_{K, \theta}^{*}$ is treated as perfectly malleable, i.e., identical to general, intersectorally mobile capital, then capacity is completely reversible $\left(\sigma_{C A P}=\infty\right)$. In the case where technologies' outputs are also perfect substitutes there will be virtually no limit on the ability of producers to scrap capital where variable costs are high and add it where they are low. Flip-flop behavior will result. ${ }^{9}$ If $\sigma_{G E N}$ is large but finite, small changes in energy prices induce substantial technology substitution, significantly moderating the macroeconomic costs of emission reductions. The intuition in both these cases is that producers adjust capacity utilization until the marginal costs of generation are equalized across technologies. CES aggregation of technologies' outputs relaxes this assumption while having minimal impact when the value of $\sigma_{C A P}$ is small, but preventing flip-flop behavior in cases where it is large.

Representing the intra- and inter-temporal aspects of technology substitution in hybrid CGE models is not a settled matter. Thus, while the techniques of model construction developed here are a convenient way to avoid many of the difficulties which attend hybrid modeling, they are unlikely to be the last word on this issue.

\section{Data, parameters and calibration}

Both models are numerically calibrated on a social accounting matrix (SAM) for US economy in the year 2000, using values for the substitution elasticities (which are based on Bovenberg and Goulder, 1996) and factor supply elasticities in Table 1 . The basic SAM is constructed from Bureau of Economic Analysis (BEA) data for 1999 on input-output transactions and the components of GDP by industry. ${ }^{10}$ The resulting benchmark table was then scaled to approximate the US economy in the year 2000 using the growth rate of real GDP, deflated to year 2000 prices, and aggregated into 11 industry groupings - five energy industries: coal, crude oil \& gas mining, natural gas distribution, petroleum refining and electric power; and six highly aggregate non-energy sectors: agriculture, energy intensive manufacturing, other manufacturing, transporta-

\footnotetext{
${ }^{9}$ Indeed, in preliminary runs of the hybrid model an equilibrium could not be computed for $\sigma_{G E N}=\infty$.

${ }^{10}$ See Sue Wing (forthcoming) for details.
} 
Table 1

Substitution and supply elasticities

\begin{tabular}{|c|c|c|c|c|c|c|c|}
\hline Sector & $\sigma_{K L E M}{ }^{\mathrm{a}}$ & $\sigma_{E}^{\mathrm{b}}$ & $\sigma_{A}^{\mathrm{c}}$ & $\sigma_{R}^{\mathrm{d}}$ & $\eta_{R}{ }^{\mathrm{e}}$ & All sectors & \\
\hline Agriculture & 0.68 & 1.45 & 2.31 & 0.4 & 0.5 & $\sigma_{K L}^{\mathrm{f}}$ & 0.7 \\
\hline Crude oil \& gas & 0.68 & 1.45 & 5.00 & 0.4 & 1.0 & $\sigma_{E M}^{\mathrm{g}}$ & 0.7 \\
\hline Coal & 0.80 & 1.08 & 1.14 & 0.4 & 2.0 & $\sigma_{M}^{\mathrm{h}}$ & 0.6 \\
\hline Refined oil & 0.74 & 1.04 & 2.21 & - & - & $\sigma_{T}{ }^{\mathrm{i}}$ & 1.0 \\
\hline Natural gas & 0.96 & 1.04 & 1.00 & - & - & $\eta_{L}{ }^{\mathrm{j}}$ & 0.3 \\
\hline Electricity & 0.81 & 0.97 & 1.00 & 0.4 & 0.5 & & \\
\hline Energy intensive mfg. & 0.94 & 1.08 & 2.74 & - & - & Electricity & \\
\hline Transportation & 0.80 & 1.04 & 1.00 & - & - & $\sigma_{F-N F}^{\mathrm{k}}$ & 10 \\
\hline Manufacturing & 0.94 & 1.08 & 2.74 & - & - & $\sigma_{G E N} 1$ & 10 \\
\hline Services & 0.80 & 1.81 & 1.00 & - & - & $\sigma_{A C T}^{\mathrm{m}}$ & 0.5 \\
\hline Rest of the economy & 0.98 & 1.07 & 1.00 & 0.4 & 1.0 & $\sigma_{C A P}{ }^{\mathrm{n}}$ & 1.0 \\
\hline
\end{tabular}

${ }^{a}$ Elasticity of substitution between value added and energy-materials composite.

${ }^{\mathrm{b}}$ Inter-fuel elasticity of substitution.

${ }^{\mathrm{c}}$ Armington elasticity of substitution.

${ }^{\mathrm{d}}$ Elasticity of substitution between KLEM composite and natural resources.

eNatural resource supply elasticity.

${ }^{\mathrm{f}}$ Capital-labor elasticity of substitution.

${ }^{\mathrm{g}}$ Elasticity of substitution between energy and material composites.

${ }^{\mathrm{h}}$ Elasticity of substitution among intermediate materials.

${ }^{\mathrm{i}}$ Elasticity of output transformation between domestic and exported commodity types.

${ }^{\mathrm{j}}$ Labor supply elasticity.

${ }^{\mathrm{k}}$ Elasticity of substitution between fossil and non-fossil electric output.

${ }^{1}$ Elasticity of substitution among generation technologies.

${ }^{\mathrm{m}}$ Elasticity of substitution among electric sector activities.

${ }^{\mathrm{n}}$ Elasticity of transformation for technology-specific capital.

tion, services, and an amalgam of the remaining industries in the economy.

The economic accounts do not record the contributions to the various sectors of the economy of key natural resources that are germane to the climate problem. Following Sue Wing (2001), information from a range of additional sources is employed to approximate these values as shares of the input of capital to the agriculture, oil and gas, mining, coal, and electric power, and rest-of-economy industries. Applying these shares allows the value of natural resource inputs to be disaggregated from the factor supply matrix, with the value of capital being decremented accordingly. The final SAM, shown in Fig. 3, along with the parameters in Table 1, specifies the numerical calibration point for the top-down model.

To calibrate the hybrid model it is necessary to disaggregate the column in the SAM which corresponds to the electric power sector. The method used here follows Sue Wing (forthcoming) in apportioning the entries in the column account among the activities $O H, T D$ and GEN, and the latter's constituent discrete generation technologies. The essence of the procedure is to minimize the deviations between the benchmark allocation of inputs to the discrete technologies and the input cost shares implied by their engineering characteristics, subject to the zeroprofit and market-clearance constraints of the bottom-up production structure in Fig. 2B.

The hybrid model distinguishes 18 specific technologies: two types of coal-fired generation (steam turbines, ST; and combined-cycle, CC), five categories of petroleum- and natural gas-fired generation (internal combustion engines, IC; combustion turbines, CT; and gas turbines, GT, in addition to ST and CC), nuclear and hydropower, and four classes of renewables. The characteristics of these technologies are shown in Table 2. Input shares for labor, capital and fuel in generation costs using the assumptions to the Annual Energy Outlook (DOE/EIA, 2003a), the prices of fuels and electricity from the Electric Power Annual (DOE/ EIA, 2003b), and additional data on capacity factors and a variety of sources. The data on net generation are from the EIA Utility Form 906 database. ${ }^{11}$ This source also tabulates data on fuel consumption by prime mover and fuel type, which are not shown. The calibration procedure computes the average cost of generation and the allocation of the remainder of the electric sector's non-energy materials, labor and capital to $T D$ and $O H$.

The resulting column disaggregation is shown in Fig. 4. The row totals indicate the total demand for each input by the electric power sector. By design, these values coming out of the hybrid calibration procedure are identical to the

\footnotetext{
${ }^{11}$ The total $\mathrm{kWh}$ of net generation in Table 2 understates total production of electricity in the year 2000 by 21 percent. The reason is that the present analysis excludes non-utility power producers, which primarily belong to other sectors of the economy (see, e.g., DOE/EIA, 2003b, Table 1.1). Since non-utility generators' usage of primary factors and intermediate fuel and non-fuel inputs do not appear in the electric sector's economic accounts and cannot be calculated from the SAM, they are omitted from the bottom-up technology calibration procedure.
} 


\begin{tabular}{|c|c|c|c|c|c|c|c|c|c|c|c|c|c|c|c|c|c|c|}
\hline & ठే & 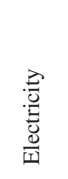 & שี & 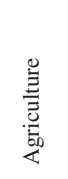 & $\begin{array}{l}\tilde{D} \\
\bar{\infty} \\
\infty \\
\overline{0} \\
\overline{0} \\
\bar{\Xi} \\
\tilde{U}\end{array}$ & 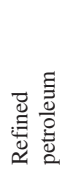 & 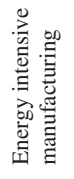 & 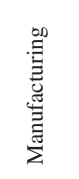 & 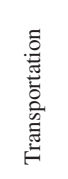 & 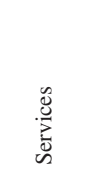 & 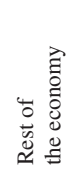 & 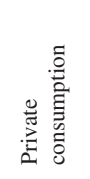 & 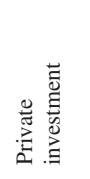 & 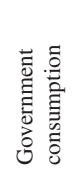 & 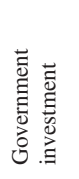 & 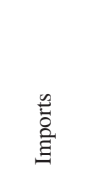 & 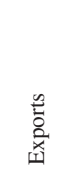 & Total \\
\hline \multirow{10}{*}{$\begin{array}{l}\text { Coal } \\
\text { Electricity } \\
\text { Gas } \\
\text { Agriculture } \\
\text { Crude oil } \\
\text { \& gas } \\
\text { Refined } \\
\text { petroleum } \\
\text { Energy } \\
\text { intensive } \\
\text { mfg. } \\
\text { Manu- } \\
\text { facturing } \\
\text { Transport. } \\
\text { Services } \\
\text { Rest of the } \\
\text { economy }\end{array}$} & 0.24 & 1.45 & 0.00 & 0.00 & 0.00 & 0.00 & 0.22 & 0.06 & 0.01 & 0.06 & 0.13 & 0.01 & \begin{tabular}{|l|}
-0.01 \\
\end{tabular} & 0.01 & \begin{tabular}{l|l|}
0.00 \\
\end{tabular} & -0.03 & 0.15 & 2.29 \\
\hline & 0.05 & 0.08 & 0.03 & 0.28 & 0.12 & 0.17 & 1.38 & 2.35 & 0.28 & 6.45 & 0.46 & 10.21 & \begin{tabular}{l|l}
0.00 \\
\end{tabular} & 2.70 & 0.00 & -0.15 & 0.05 & 24.47 \\
\hline & 0.00 & 0.53 & 2.28 & 0.04 & 0.45 & 0.25 & 0.82 & 0.73 & 0.06 & 1.22 & 0.21 & 3.53 & 0.00 & 0.61 & 0.00 & 0.00 & 0.04 & 10.76 \\
\hline & 0.00 & 0.01 & 0.00 & 7.03 & 0.00 & 0.01 & 0.17 & 14.88 & 0.01 & 3.07 & 0.72 & 3.85 & \begin{tabular}{l|l|}
-0.09 \\
\end{tabular} & 0.31 & 0.00 & -2.49 & 1.88 & 29.37 \\
\hline & 0.00 & 0.02 & 4.80 & 0.00 & 2.68 & 8.38 & 0.94 & 0.02 & 0.03 & 0.06 & 0.04 & 0.00 & 0.07 & 0.01 & 0.00 & -6.53 & 0.34 & 10.86 \\
\hline & 0.07 & 0.24 & 0.04 & 0.47 & 0.07 & 1.75 & 0.63 & 0.61 & 2.43 & 2.14 & 1.73 & 6.43 & 0.13 & 1.91 & 0.00 & -1.54 & 1.00 & 18.10 \\
\hline & 0.10 & 0.12 & 0.02 & 1.42 & 0.29 & 0.51 & 17.43 & 29.83 & 0.18 & 6.81 & 9.47 & 7.13 & 0.89 & 2.11 & 0.01 & -11.47 & 7.96 & 72.82 \\
\hline & 0.34 & 0.35 & 0.05 & 3.16 & 0.18 & 0.19 & 5.51 & 91.16 & 2.28 & 43.48 & 24.57 & 108.95 & 71.89 & 10.67 & 7.44 & -84.41 & 46.88 & 332.69 \\
\hline & \begin{tabular}{|l|}
0.16 \\
0.39
\end{tabular} & $\begin{array}{l}0.95 \\
2.27\end{array}$ & $\begin{array}{l}0.13 \\
0.74\end{array}$ & $\begin{array}{l}0.88 \\
4.78\end{array}$ & \begin{tabular}{|l|}
0.12 \\
3.99 \\
\end{tabular} & \begin{tabular}{l|l|}
0.78 \\
2.26
\end{tabular} & $\begin{array}{r}3.55 \\
10.78 \\
\end{array}$ & $\begin{array}{r}7.68 \\
49.31 \\
\end{array}$ & $\begin{array}{r}9.80 \\
11.17\end{array}$ & $\begin{array}{r}8.30 \\
240.36\end{array}$ & $\begin{array}{r}2.98 \\
25.59\end{array}$ & $\begin{array}{r}14.70 \\
500.94\end{array}$ & \begin{tabular}{|r|}
1.38 \\
40.24 \\
\end{tabular} & \begin{tabular}{|l|}
2.62 \\
5.28
\end{tabular} & \begin{tabular}{|l|}
0.12 \\
5.70 \\
\end{tabular} & $\begin{array}{r}-1.54 \\
0.73\end{array}$ & \begin{tabular}{|r|}
6.65 \\
20.57 \\
\end{tabular} & $\begin{array}{r}59.24 \\
925.08\end{array}$ \\
\hline & 0.02 & 2.51 & 1.11 & 0.40 & 0.52 & 0.35 & 3.51 & 4.97 & 2.60 & 24.81 & 2.69 & 5.95 & 58.87 & 115.31 & 19.01 & -15.40 & 10.83 & 238.06 \\
\hline \multirow{3}{*}{$\begin{array}{l}\text { Labor } \\
\text { Capital } \\
\text { Resources }\end{array}$} & 0.44 & 4. & 0.43 & 4.19 & 0.67 & 1.14 & 16.13 & 84.31 & 19.03 & 53.96 & 111.49 & & & & & & & 596.21 \\
\hline & 0.17 & 8.39 & 0.87 & 7.67 & 0.84 & 2.11 & 10.81 & 41.03 & 9.79 & 187.89 & 66.51 & & & & & & & 336.07 \\
\hline & 0.11 & 0.44 & 0.00 & 0.16 & 0.69 & 0.00 & 0.00 & 0.00 & 0.00 & 0.00 & 7.39 & & & & & & & 8.79 \\
\hline \multirow{2}{*}{$\begin{array}{l}\text { Taxes } \\
\text { Subsidies }\end{array}$} & 0.20 & 2.69 & 0.26 & 0.63 & 0.26 & 0.20 & 0.94 & 5.77 & 1.71 & 47.31 & 1.26 & & & & & & & 61.23 \\
\hline & 0.00 & 0.00 & 0.00 & -1.72 & 0.00 & 0.00 & 0.00 & 0.00 & -0.13 & -0.82 & $\begin{array}{r}-17.19 \\
\end{array}$ & & & & & & & -19.87 \\
\hline Total & 2.29 & 24.47 & 10.76 & 29.37 & 10.86 & 18.10 & 72.82 & 332.69 & 59.24 & 925.08 & 238.06 & 661.69 & 173.37 & 141.55 & 32.28 & -122.84 & 96.37 & \\
\hline
\end{tabular}

Value added $=$ GDP $=9.82$ Trillion dollars; Gross Output $=17.24$ Trillion dollars

Fig. 3. Year 2000 social accounting matrix for the US $\left(2000\right.$ Dollars $\left.\times 10^{10}\right)$. Value added $=$ GDP $=9.82$ trillion dollars; Gross output $=17.24$ trillion dollars. Source: Bureau of economic analysis; author's calculations and assumptions.

corresponding entries in the electricity industry column of the SAM in Fig. 3, implying that the general equilibrium interactions between the electricity sector and the rest of the economy will be similar for both the hybrid and the top-down models. This common database ensures that comparisons of the model's behavior reflect only structural and parametric differences, guaranteeing the given degree of technological optimism.

To simulate the economic effects of taxes on $\mathrm{CO}_{2}$ emissions, the demands for fossil fuels by industries and the representative agent are linked to emissions of $\mathrm{CO}_{2}$ though aggregate emission factors. The latter assume a fixed stoichiometric relationship between the benchmark value of aggregate demand for each fossil-fuel commodity and the $\mathrm{CO}_{2}$ emitted from the use of that fuel in the base year. ${ }^{12}$ The resulting coefficients serve to translate the carbon tax into a vector of ad valorem taxes on fossil fuels which differentiated by carbon content. For each model, the simulation experiments first replicate the year 2000 benchmark equilibrium as the no-policy counterfactual, and then compute a series of distorted equilibria with emission taxes

\footnotetext{
${ }^{12}$ Fossil-fuel emissions of carbon in the base year were divided by commodity use in the SAM (calculated as gross output-net exports). $\mathrm{CO}_{2}$ emissions in the year 2000 from coal, petroleum and natural gas are 2112, 2439 and $1244 \mathrm{MT}$, respectively (DOE/EIA, 2003c), while the aggregate use of these commodities in the SAM is $21.8,186.5$ and 107.1 billion dollars, respectively. The emission coefficients for coal, petroleum and natural gas are thus $0.097,0.012$ and 0.013 tons of $\mathrm{CO}_{2}$ per dollar, respectively.
}

of $\$ 50, \$ 100, \$ 150$ and $\$ 200$ per ton of carbon. ${ }^{13}$ The revenue from these taxes is recycled to the representative agent as a lump-sum transfer.

\section{Results and discussion}

This section presents four sets of simulation results. The effect of carbon taxes on individual generation technologies and the electricity sector in the hybrid model is first introduced, and then the general equilibrium effects of the changes in the generation portfolio are analyzed. There follows a comparison of the behavior of the top-down and the hybrid model, as well as a sensitivity analysis which highlights the importance of capital malleability for the macroeconomic costs of climate policy.

\subsection{Technology dynamics in electric power generation}

The first set of results characterizes the effects of $\mathrm{CO}_{2}$ emission taxes on both individual generation technologies and the electric power sector as a whole. The response of the technologies' levels of output to the tax is shown in

\footnotetext{
${ }^{13} \mathrm{~A}$ potential source of confusion in that the taxes are specified in units of carbon while environmental statistics usually account for GHG emissions in units of $\mathrm{CO}_{2}$. The ratio of these substances' molecular weights $\left(0.273\right.$ tons of carbon per ton of $\left.\mathrm{CO}_{2}\right)$ establishes an equivalency between the two measures. The corresponding taxes on carbon dioxide are less than one-third as large as the carbon taxes in the text: \$13.6, \$27.3, $\$ 40.9$ and $\$ 54.5$ per ton of $\mathrm{CO}_{2}$.
} 
Table 2

Technology characteristics in the hybrid model

\begin{tabular}{|c|c|c|c|c|c|c|c|c|}
\hline \multirow[t]{2}{*}{ Technology } & \multicolumn{6}{|c|}{ Cost shares } & \multicolumn{2}{|c|}{ Generation characteristics (year 2000) } \\
\hline & Labor & Capital & Coal & Oil & Nat. gas & Nat. res. & Net gen. $\left(10^{12} \mathrm{~kW} \mathrm{~h}\right)$ & Avg. cost (cents/kW h) \\
\hline \multicolumn{9}{|l|}{ Coal } \\
\hline $\mathrm{ST}^{\mathrm{a}}$ & 0.15 & 0.54 & 0.32 & - & - & - & 1.698 & 2.7 \\
\hline $\mathrm{CC}^{\mathrm{b}}$ & 0.16 & 0.58 & 0.26 & - & - & - & 0.002 & 2.7 \\
\hline \multicolumn{9}{|l|}{ Oil } \\
\hline $\mathrm{IC}^{\mathrm{c}}$ & 0.09 & 0.11 & - & 0.80 & - & - & 0.001 & 4.0 \\
\hline$G T^{d}$ & 0.08 & 0.09 & - & 0.83 & - & - & 0.005 & 4.0 \\
\hline $\mathrm{ST}^{\mathrm{a}}$ & 0.09 & 0.11 & - & 0.80 & - & - & 0.062 & 4.3 \\
\hline $\mathrm{CT}^{\mathrm{e}}$ & 0.09 & 0.11 & - & 0.81 & - & - & 0.001 & 4.0 \\
\hline $\mathrm{CC}^{\mathrm{b}}$ & 0.07 & 0.15 & - & 0.78 & - & - & $1.5 \times 10^{-4}$ & 3.0 \\
\hline \multicolumn{9}{|l|}{ Gas } \\
\hline $\mathrm{IC}^{\mathrm{c}}$ & 0.07 & 0.12 & - & - & 0.80 & - & $5.1 \times 10^{-4}$ & 3.5 \\
\hline $\mathrm{GT}^{\mathrm{d}}$ & 0.07 & 0.10 & - & - & 0.83 & - & 0.022 & 3.4 \\
\hline $\mathrm{ST}^{\mathrm{a}}$ & 0.08 & 0.13 & - & - & 0.79 & - & 0.208 & 2.0 \\
\hline $\mathrm{CT}^{\mathrm{e}}$ & 0.08 & 0.14 & - & - & 0.77 & - & 0.051 & 3.2 \\
\hline $\mathrm{CC}^{\mathrm{b}}$ & 0.08 & 0.23 & - & - & 0.69 & - & 0.007 & 2.9 \\
\hline \multicolumn{9}{|c|}{ Nuclear and renewables } \\
\hline Hydro & 0.24 & 0.56 & - & - & - & 0.19 & 0.706 & 1.1 \\
\hline Nuclear & 0.13 & 0.61 & - & - & - & 0.27 & 0.248 & 4.3 \\
\hline Wind & 0.17 & 0.63 & - & - & - & 0.20 & $7.8 \times 10^{-6}$ & 3.0 \\
\hline Solar & 0.07 & 0.73 & - & - & - & 0.20 & $2.5 \times 10^{-7}$ & 10.1 \\
\hline Biomass & 0.18 & 0.61 & - & - & - & 0.21 & 0.001 & 3.6 \\
\hline Geothermal & 0.24 & 0.56 & - & - & - & 0.20 & $6.5 \times 10^{-4}$ & 2.4 \\
\hline \multicolumn{9}{|c|}{ All technologies } \\
\hline Total & & & & & & & 3.01 & 2.5 \\
\hline
\end{tabular}

Source: Sue Wing (forthcoming).

anternal combustion engines.

${ }^{\mathrm{b}}$ Gas turbines.

${ }^{\mathrm{c}}$ Steam turbines.

${ }^{\mathrm{d}}$ Combustion turbines.

${ }^{\mathrm{e}}$ Combined cycle turbines.

Fig. 5. ${ }^{14}$ The dynamics are for the most part what one might expect, with a very large decline in the output of coal-fired generation being partially offset by a corresponding increase in technologies that use other fuels with lower carbon contents.

Electricity production by oil-fired and natural gas-fired technologies expands. This increase is concentrated in baseload conventional steam turbine technologies, which are responsible for much of the substitution for pulverized coal. Intermediate-load gas-fired combustion turbine and gas turbine generation both see large increases, with the output of oil-fired gas turbine units rising by a somewhat smaller amount. Peaking technologies such as oil- or gasfired internal combustion or combined-cycle units see similar percentage increases to the other technologies, but remain a sufficiently small share of the overall generation portfolio that they have little impact. There is a marked expansion in renewable generation, particularly in hydro, geothermal and biomass technologies. The outputs of high-

\footnotetext{
${ }^{14}$ The arrows on each chart indicate the axis to which a given series corresponds.
}

cost alternative technologies such as a solar and wind expand as well, but their impact remains negligible.

A somewhat surprising feature of Fig. 5 is that the output of nuclear electric generation stays essentially flat. This result arises from competition at the margin between nuclear and hydrogeneration for the electricity sector's generic natural resource. From the input shares in Fig. 4 it is clear that while both technologies have similar capital intensities, nuclear is less labor intensive and more resource intensive. Therefore, because carbon taxes cause the price of the electric power resource to increase dramatically relative to the wage, as shown in Table 3, nuclear's output falls while hydro's expands.

The extent to which this situation reflects reality is unclear. Within the model's simulated economy the shares of nuclear and hydro in total net electricity generation depend on the interaction of these technologies' demands for the electric power resource, $v_{R, \theta}$, with the elasticity of total resource supply, $\eta_{R}$. As pointed out in Sue Wing (forthcoming), there is significant uncertainty surrounding the true value of $v_{R, \theta}$. Moreover, the true value of $\eta_{R}$, which reflects the ease with which land may be re-allocated from 
GEN

\begin{tabular}{|c|c|c|c|c|c|c|c|c|c|c|c|c|c|c|c|c|c|c|c|c|c|}
\hline & \multicolumn{2}{|c|}{$\begin{array}{l}\text { Coal } \\
\end{array}$} & \multicolumn{5}{|c|}{ Natural Gas } & \multicolumn{5}{|c|}{ Petroleum } & \multicolumn{6}{|c|}{ Non-Fossil } & \\
\hline & & & ST & $\mathrm{CC}$ & IC & GT & ST & $\mathrm{CT}$ & $\mathrm{CC}$ & IC & GT & ST & $\mathrm{CT}$ & $\mathrm{CC}$ & Hydro & Nucl. & Wind & Solar & Bio. & Geo. & \\
\hline \multirow{2}{*}{$\begin{array}{l}\text { Coal } \\
\text { Electric } \\
\text { Power }\end{array}$} & & & \begin{tabular}{|l|l|}
1.446 \\
\end{tabular} & $\begin{array}{l}0.001 \\
\end{array}$ & & - & & & & - & & & & & & & & & - & & 1.448 \\
\hline & 0.011 & 0.073 & -1 & & & - & & - & & - & & $\begin{array}{lll}- & \end{array}$ & - & & & - & & - & - & & 0.084 \\
\hline \multirow{3}{*}{$\begin{array}{l}\text { Natural Gas } \\
\text { Agricilture } \\
\text { Crude } \\
\text { Oil \& Gas }\end{array}$} & & & - & & 0.001 & 0.06 & $\begin{array}{l}0.327 \\
\end{array}$ & 0.123 & 0.014 & 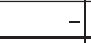 & & - & - & & & - & & - & - & & 0.526 \\
\hline & \begin{tabular}{|l|}
0.002 \\
\end{tabular} & 0.013 & - & & & - & & - & & - & & - & - & & & - & & & 7 & & 0.015 \\
\hline & 0.003 & 0.021 & - & & & - & & - & & t & & - & - & & & - & & - & 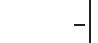 & & 0.024 \\
\hline \multirow{2}{*}{$\begin{array}{l}\text { Petroleum } \\
\text { Energy } \\
\text { Intensive } \\
\text { Mfg. }\end{array}$} & & & - & & & - & & - & & 0.004 & \begin{tabular}{|l|l|}
0.018 \\
\end{tabular} & \begin{tabular}{|l|}
0.212 \\
\end{tabular} & 0.003 & $3.6 \times 10^{-4}$ & & - & & - & -1 & & 0.238 \\
\hline & 0.016 & 0.105 & & & & & & & & & & & & & & & & & & & 121 \\
\hline \multirow{2}{*}{$\begin{array}{l}\text { Other Mfg. } \\
\text { Transport- } \\
\text { ation }\end{array}$} & \begin{tabular}{|l|l|}
0.047 \\
\end{tabular} & 0.303 & - & & & & & & & & & & & & & & & & - & & 0.350 \\
\hline & 0.127 & 0.819 & - & & - & - & & $\begin{array}{lll}- & -1\end{array}$ & & - & & - & - & & & - & & & -1 & & 0.945 \\
\hline \multirow{2}{*}{$\begin{array}{l}\text { Services } \\
\text { Rest-of- } \\
\text { Economy }\end{array}$} & \begin{tabular}{|l|l|}
0.304 \\
\end{tabular} & 1.962 & - & & - & - & 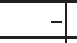 & - & & - & & - & - & & & - & & - & - & & 2.265 \\
\hline & 0.337 & 2.175 & - & & - & - & - & 7 & & - & 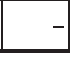 & - & - & & _. & - & & - & - & & 2.512 \\
\hline \multirow{3}{*}{$\begin{array}{l}\text { Labor } \\
\text { Capital } \\
\text { Natural } \\
\text { Resource }\end{array}$} & \begin{tabular}{|l|l|}
0.406 \\
\end{tabular} & 2.934 & 0.67 & $8.1 \times 10^{-4}$ & $1.3 \times 10^{-4}$ & 0.005 & \begin{tabular}{|l|l|}
0.032 \\
\end{tabular} & 0.013 & 0.002 & $4.8 \times 10^{-4}$ & \begin{tabular}{|l}
0.002 \\
\end{tabular} & \begin{tabular}{|l|}
0.024 \\
\end{tabular} & $3.4 \times 10^{4}$ & $3.3 \times 10^{-5}$ & $\mid 0.195$ & \begin{tabular}{|l|}
0.138 \\
\end{tabular} & $3.9 \times 10^{-6}$ & $1.8 \times 10^{-7}$ & $6.5 \times 10^{4}$ & $3.8 \times 10^{4}$ & 4.422 \\
\hline & \begin{tabular}{|l|}
0.674 \\
\end{tabular} & $\begin{array}{l}4.037 \\
\end{array}$ & \begin{tabular}{|l|}
2.446 \\
\end{tabular} & $\begin{array}{ll}0.003 \\
\end{array}$ & $2.2 \times 10^{-4}$ & 0.008 & $\begin{array}{l}0.056 \\
\end{array}$ & 0.023 & 0.005 & $5.9 \times 10^{-4}$ & \begin{tabular}{|l|l|}
0.002 \\
\end{tabular} & \begin{tabular}{|l|l|}
0.029 \\
\end{tabular} & $4.1 \times 10^{4}$ & $6.7 \times 10^{-5}$ & \begin{tabular}{|l|}
0.451 \\
\end{tabular} & \begin{tabular}{|l|l|}
0.651 \\
\end{tabular} & $1.5 \times 10^{-5}$ & $1.9 \times 10^{-6}$ & 0.002 & $8.8 \times 10^{-4}$ & 8.389 \\
\hline & & & - & & & - & & & & & & - & & & 0.153 & 0.288 & $4.6 \times 10^{-6}$ & $5.1 \times 10^{-7}$ & $7.6 \times 10^{-4} \mid$ & $3.1 \times 10^{-4}$ & 0.442 \\
\hline \multicolumn{3}{|l|}{ Generation } & \multicolumn{2}{|c|}{4.567} & \multicolumn{5}{|c|}{0.669} & \multicolumn{5}{|c|}{0.296} & \multicolumn{6}{|c|}{1.880} & 7.413 \\
\hline Total & 927 & 12.441 & \begin{tabular}{|l|l|}
4.562 \\
\end{tabular} & \begin{tabular}{|l|l|}
0.005 \\
\end{tabular} & 0.002 & \begin{tabular}{|l|l|}
0.072 \\
\end{tabular} & \begin{tabular}{|l|l|}
0.416 \\
\end{tabular} & 0.160 & \begin{tabular}{|l|}
0.020 \\
\end{tabular} & 0.005 & \begin{tabular}{|l|l|}
0.021 \\
\end{tabular} & \begin{tabular}{|l|l|}
0.266 \\
\end{tabular} & 0.004 & $4.6 \times 10^{-4}$ & \begin{tabular}{|l|l|l|l|l|l|} 
& \\
\end{tabular} & \begin{tabular}{|l|}
1.077 \\
\end{tabular} & $2.3 \times 10^{-5}$ & $2.6 \times 10^{-6}$ & 0.004 & 0.002 & 1.781 \\
\hline
\end{tabular}

Fig. 4. Electric power sector detail in the hybrid model SAM (2000 dollars $\left.\times 10^{10}\right)$. Source: Sue Wing (forthcoming).

other uses in the economy to the mining of uranium, the damming of rivers or the erection of wind turbines, is not known, with the value given in Table $1(0.5)$ being little more than a plausible guess. Thus, while nuclear's constancy is an artifact of the model's structure and parameterization, its realism hinges on the homogeneity of the electric sector natural resource, and the intensity of competition among carbon-free generation technologies for its use as an input. ${ }^{15}$

Further insight into this phenomenon may be gained by examining how generation costs respond to the carbon tax. Fig. 6 shows the average costs of generation, which are estimated by multiplying the benchmark costs in Table 2 by the price indices of technologies' outputs computed by the model. ${ }^{16}$ The response of costs is almost linear over the range of carbon taxes considered, reflecting the Leontief specification of generation. The cost of coal-fired generation increases sharply with the tax, rising by rises by 0.6 percent with each incremental dollar per ton of carbon. The costs of oil and natural gas technologies increase both at a slower rate of approximately 0.4 percent per

\footnotetext{
${ }^{15}$ The inelastic resource supply implied by the low value of $\eta_{R}$ reflects the assumption that the expansion of technologies such as nuclear, hydro and wind is constrained in the short run (e.g., opposition from local landowners). A more detailed representation of inter-technology competition could model each non-fossil technology as having its own natural resource and corresponding fixed-factor supply elasticity. Assuming elasticity values that are sufficiently large for nuclear and a sufficiently small for hydro will likely result in an expansion of the former and a contraction of the latter. However, such an approach is impracticable because of the lack of data on differentiated primary electricity resources or the priceresponsiveness of their supplies.

${ }^{16}$ The model's numerical calibration procedure sets the values of these indices to unity in the counterfactual solution.
}

additional dollar per ton of carbon. The costs of hydro and geothermal technologies increase at a similar rate, but those of nuclear and biomass rise faster, at a rate of 0.5 percent per additional dollar of tax. Nuclear's cost thereby remains the highest of all the conventional generation technologies, which accounts for its lack of expansion.

Fig. 7 shows that carbon taxes induce sizeable adjustments in the capacity of the different technologies. Increases in the capacity rent are associated with demand for additional capacity, while decreases in the rent indicate demand for capacity retirement. Panel A shows dramatic declines in the rents for coal capacity and increases in the capacity rents for all other electricity sources. The largest increases occur in oil-fired generation, followed by natural gas, renewables and nuclear electricity. These changes are mirrored by movements in the levels of technology specific capital in Panel B. Coal-fired technologies experience retirement of 30-80 percent of their capacity, while natural gas generating capacity expands by $40-100$ percent, and oil-fired capacity expands by $50-135$ percent. Capacity for carbon-free electric generation expands by a modest amount, up to 27 percent in hydro and only 5 percent in nuclear. The response of capacity rents to the tax generally exceeds that of capacity levels, as would be expected where retirement and retrofit is very costly, with $v_{K, \theta}^{*}$ for each technology being inelastically supplied.

The results differ from Boehringer (1998, Fig. 3), where the quantities of base load coal and hydrogeneration remain essentially constant, first oil-fired, and then at high tax levels gas-fired generation decline to zero, and there is a partially offsetting influx of wind power. There are two reasons for this divergence: differences in the specification 

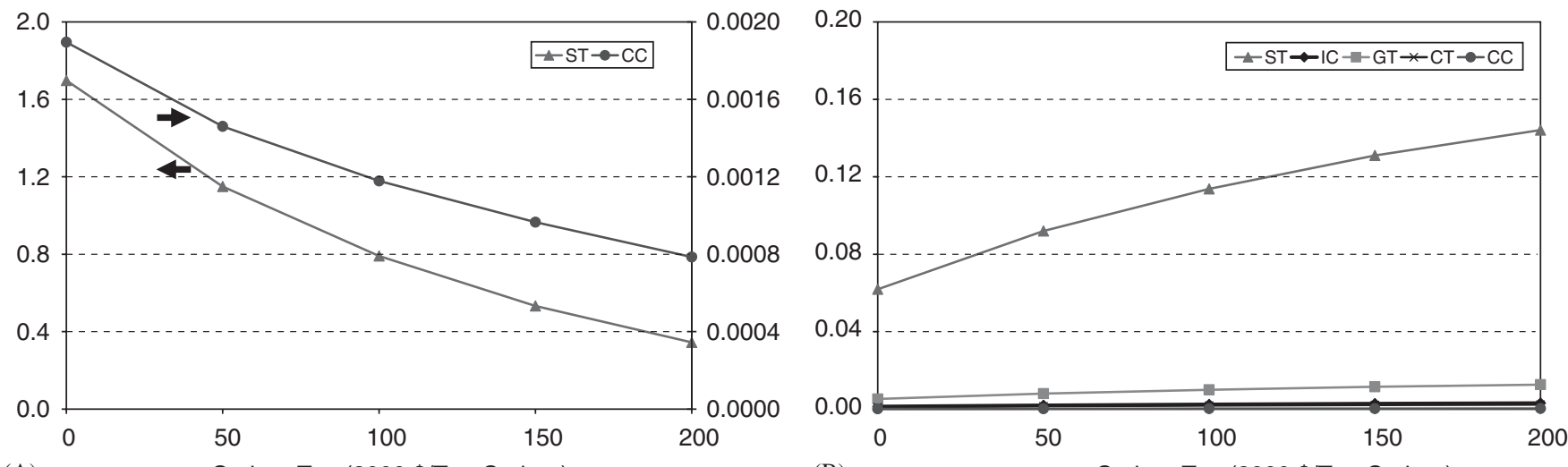

(A)

Carbon Tax (2000 \$/Ton Carbon)

(B)

Carbon Tax (2000 \$/Ton Carbon)

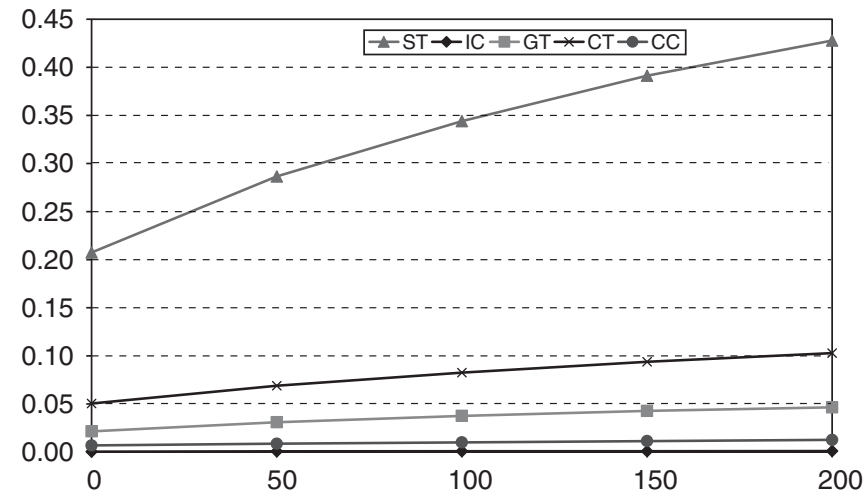

(C)

Carbon Tax (2000 \$/Ton Carbon)

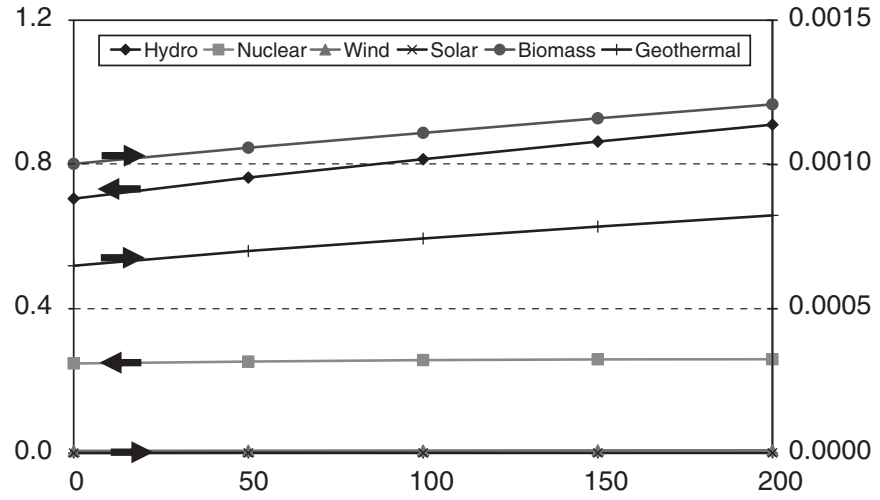

(D)

Carbon Tax (2000 \$/Ton Carbon)

Fig. 5. Electric power technology dynamics in the hybrid model: net generation (Trillion $\mathrm{kW} \mathrm{h):} \mathrm{(A)} \mathrm{coal,} \mathrm{(B)} \mathrm{oil,} \mathrm{(C)} \mathrm{natural} \mathrm{gas,} \mathrm{and} \mathrm{(D)} \mathrm{non-fossil.}$

Table 3

Effects of carbon taxes on prices (percent change from no-tax levels)

\begin{tabular}{|c|c|c|c|c|c|c|c|c|}
\hline \multirow[t]{2}{*}{ Carbon tax $(2000 \$ /$ ton C $)$} & \multicolumn{4}{|c|}{ Hybrid model } & \multicolumn{4}{|c|}{ Top-down model } \\
\hline & 50 & 100 & 150 & 200 & 50 & 100 & 150 & 200 \\
\hline \multicolumn{9}{|c|}{ Commodity prices (gross-of-tax) } \\
\hline Coal & 133 & 264 & 392 & 515 & 131 & 265 & 397 & 529 \\
\hline Electricity & 9 & 16 & 23 & 28 & 8 & 12 & 16 & 19 \\
\hline Natural gas & 18 & 35 & 53 & 70 & 17 & 35 & 53 & 70 \\
\hline Agriculture & -0.1 & -0.1 & -0.2 & -0.2 & -0.1 & -0.1 & -0.1 & -0.1 \\
\hline Crude oil \& gas & -3.8 & -6.7 & -9.1 & -11.1 & -4.0 & -7.2 & -9.8 & -11.9 \\
\hline Oil & 16 & 33 & 50 & 67 & 17 & 34 & 51 & 68 \\
\hline Energy intensive $\mathrm{mfg}$. & 0.4 & 0.7 & 0.9 & 1.1 & 0.4 & 0.7 & 0.9 & 1.1 \\
\hline Manufacturing & -0.2 & -0.3 & -0.4 & -0.5 & -0.1 & -0.2 & -0.3 & --0.4 \\
\hline Transportation & 0.3 & 0.7 & 1.0 & 1.3 & 0.3 & 0.7 & 1.1 & 1.4 \\
\hline Services & -0.5 & -0.9 & -1.2 & -1.5 & -0.5 & -0.8 & -1.1 & -1.4 \\
\hline Rest of economy & -0.4 & -0.7 & -1.0 & -1.2 & -0.4 & -0.6 & -0.9 & -1.0 \\
\hline \multicolumn{9}{|l|}{ Factor prices } \\
\hline Labor & -0.01 & -0.01 & -0.02 & -0.02 & -0.01 & -0.01 & -0.01 & -0.02 \\
\hline Capital & -0.01 & -0.02 & -0.03 & -0.03 & -0.01 & -0.02 & -0.02 & -0.03 \\
\hline \multicolumn{9}{|l|}{ Natural resources } \\
\hline Coal & -75 & -91 & -96 & -97 & -87 & -96 & -98 & -99 \\
\hline Electricity & 51 & 114 & 186 & 261 & 78 & 142 & 199 & 250 \\
\hline Agriculture & -1.1 & -2.2 & -3.3 & -4.2 & -1.3 & -2.4 & -3.3 & -4.2 \\
\hline Crude oil \& gas & -29 & -47 & -60 & -68 & -33 & -53 & -67 & -75 \\
\hline Rest of economy & -0.1 & -0.2 & -0.4 & -0.5 & -0.2 & -0.4 & -0.6 & -0.8 \\
\hline
\end{tabular}



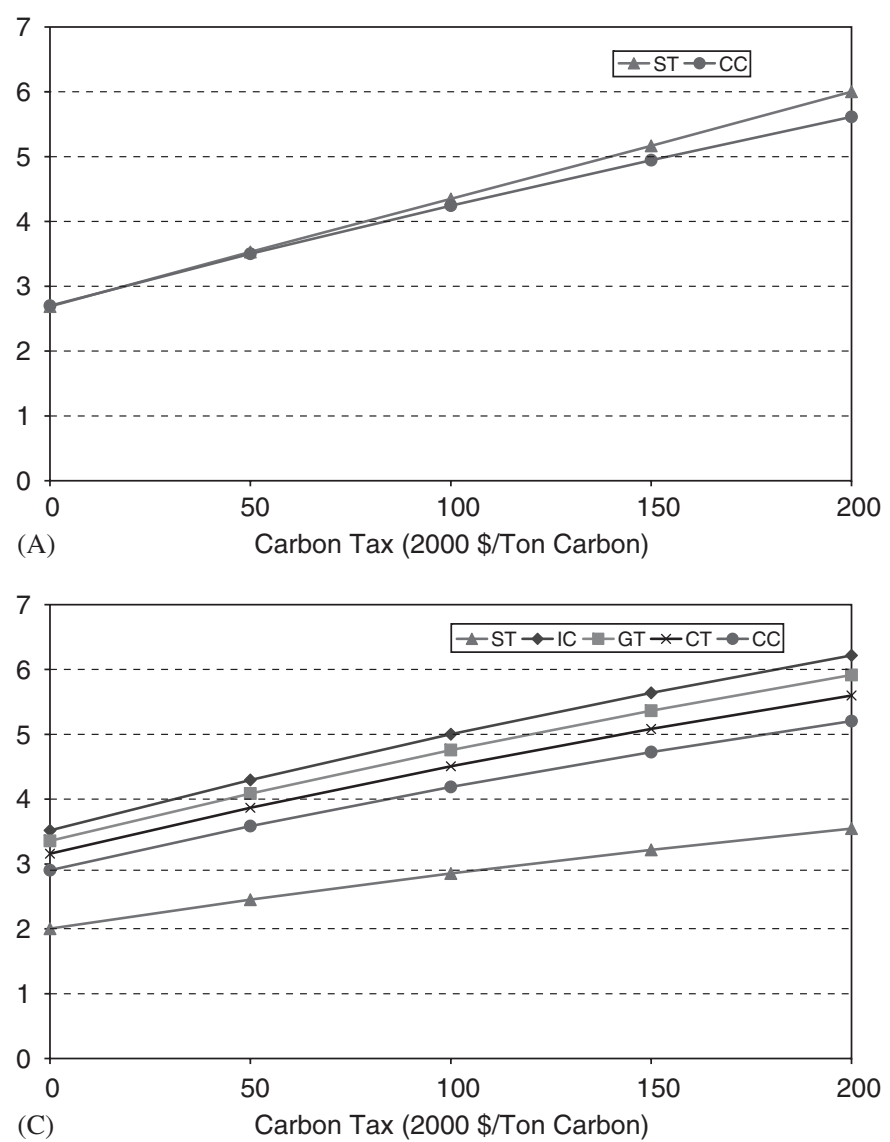
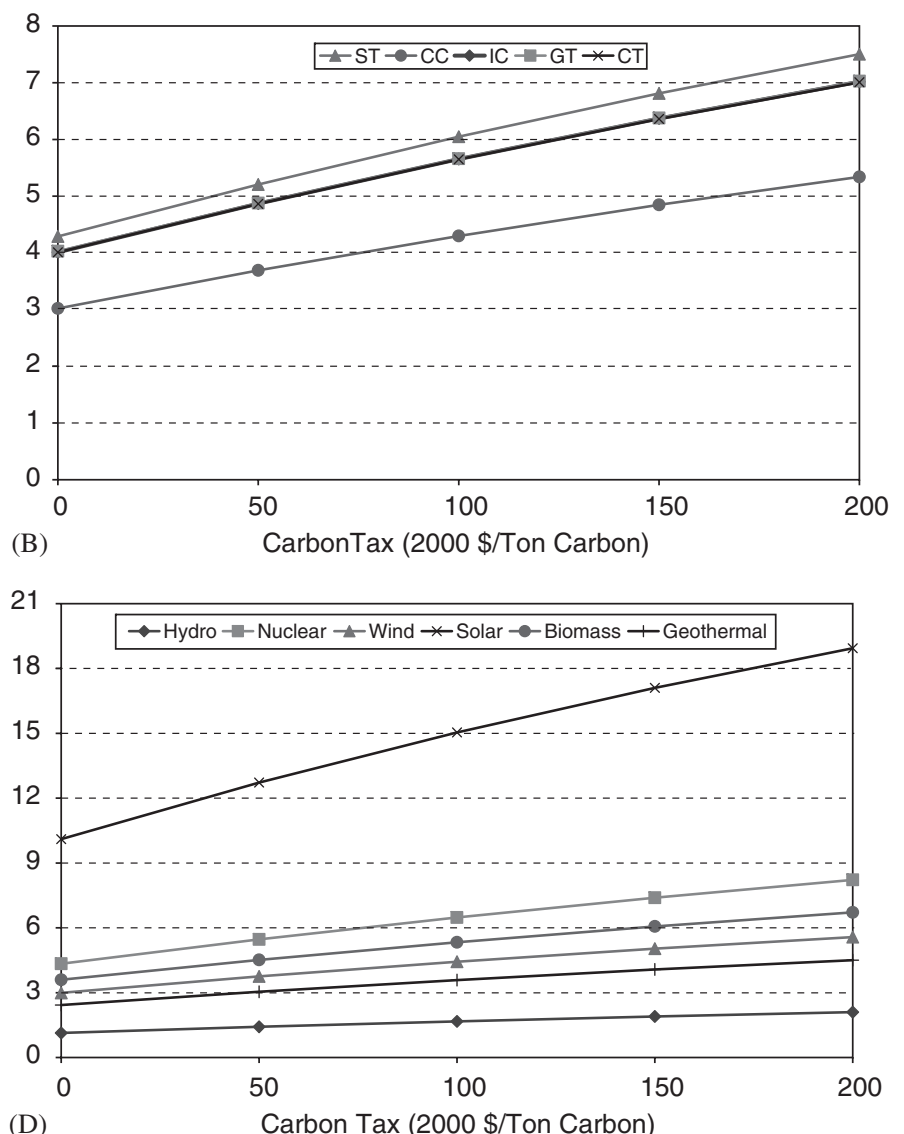

(D)

Carbon Tax (2000 \$/Ton Carbon)

Fig. 6. Electric power technology dynamics in the hybrid model: Average generation costs (2000 Cents/kW h): (A) coal, (B) oil, (C) natural gas, and (D) non-fossil.

of the policy shock, and difference in the supply elasticity of technology-specific capital.

Boehringer examines the effect of an ad valorem tax on the primary energy inputs to electricity production - not a broad-based tax on $\mathrm{CO}_{2}$ - which will have different general equilibrium effects compared to the shocks simulated here. More importantly, treating the endowments of technologies' specific capital-cum-capacity as perfectly inelastic makes capacity in his model irreversible, which explains the lack of retirement of coal generation or expansion of competing conventional generation which are the key features of the present results. This result indicates the importance of capacity malleability, whose implications will be explored more fully below.

The consequences for the electric sector as a whole are summarized in Fig. 8. Panel A shows that the dynamics described above result in a decline in the overall level of net generation of 8-25 percent, while shifting the composition of the generation portfolio away from high-carbon fossil fuels such as coal toward low-carbon fossil fuels such as gas, and carbon-free sources of electricity such as hydro. ${ }^{17}$ Carbon taxes precipitate a dramatic reduction in coal-fired

\footnotetext{
${ }^{17}$ Renewable technologies such as wind and solar constitute such a small share of total net generation that their collective contribution is not discernable.
}

generation, creating a supply gap which is filled by large increases in natural gas and hydrogeneration. Oil-fired generation expands as well, but even at high levels of the tax makes only a modest contribution to electric output. Nuclear electricity generation remains flat.

Panel B highlights both the change in the average cost of electricity generation and the shift in its components. Compared to the benchmark value of 2.5 cents per $\mathrm{kW} \mathrm{h}$, a $\$ 200 /$ ton carbon tax increases average generation costs by 60 percent. Coal generation, which initially makes up just under three-fifths of this total, shrinks by one-third. The costs of oil- and gas-fired technologies both expand fivefold, from 0.1 to 0.5 and 0.2 to 1.1 cents per $\mathrm{kWh}$, respectively. Hydro and nuclear, which together made up the second largest components of benchmark average electricity costs, treble, rising from 0.3 to 0.8 and 0.4 to 0.9 cents per $\mathrm{kWh}$, respectively.

Panels C and D illustrate how the activity levels of overhead, transmission and distribution, generation, and the entire electric sector respond to the tax. $O H$ and $T D$ are largely unaffected, shrinking by about $1-5$ percent relative to their baseline levels. The impact on $G E N$ is much larger, exhibiting a decline of 14-33 percent. The overall effect is to reduce the output of the electric sector by $6-17$ percent. These changes in quantities are mirrored by shifts in prices. The marginal costs of $\mathrm{OH}$ and $T D$ fall by less than one 

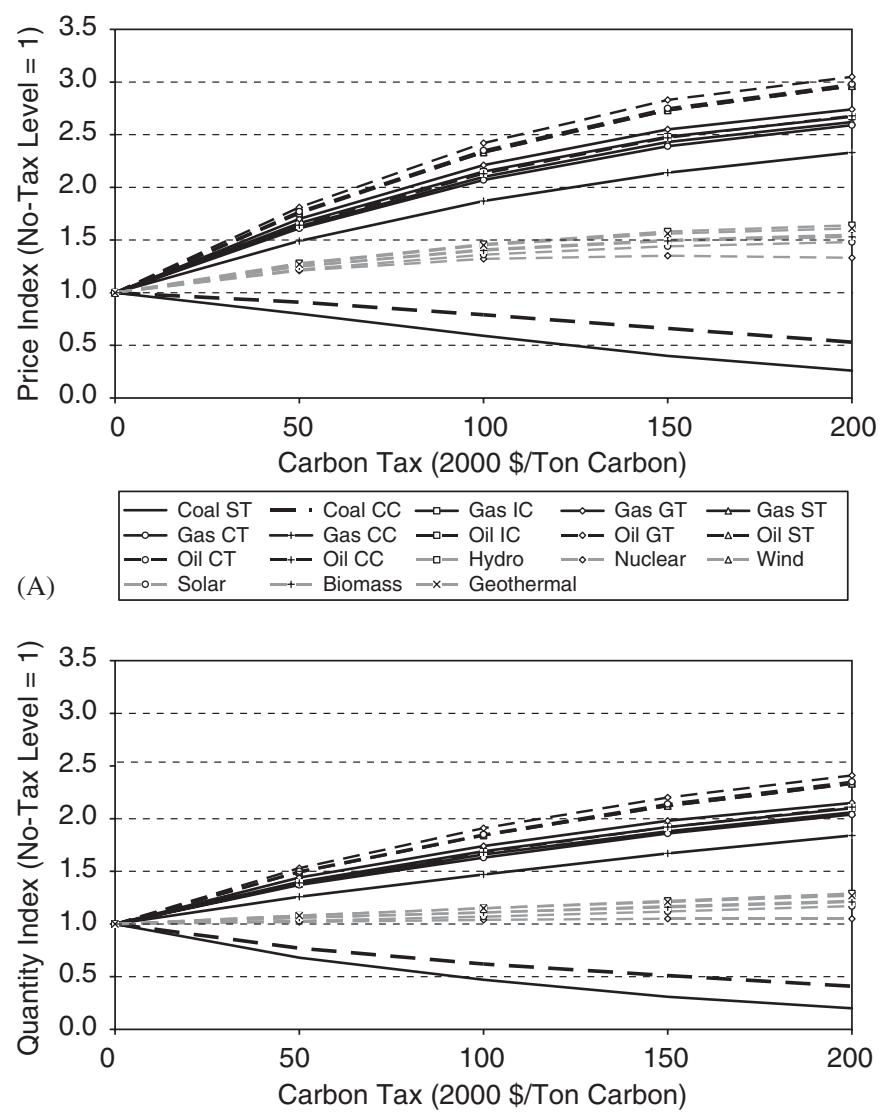

(B)

\begin{tabular}{|c|c|c|c|c|}
\hline $\begin{array}{l}\text { - Coal ST } \\
-\propto \text { Gas CT } \\
-\circ-\text { Oil CT } \\
-\circ-\text { Solar }\end{array}$ & $\begin{array}{l}- \text { - Coal CC } \\
-+- \text { Gas CC } \\
++- \text { Oil CC } \\
-+- \text { Biomass }\end{array}$ & $\begin{array}{l}-- \text { Gas IC } \\
-- \text { Oil IC } \\
--- \text { Hydro } \\
-x-\text { Geothern }\end{array}$ & $\begin{array}{l}\longrightarrow \text { Gas GT } \\
\because-\text { Oil GT } \\
\because-\text { Nuclear } \\
\text { nal }\end{array}$ & $\begin{array}{l}\square-\text { Gas ST } \\
-\Delta-\text { Oil ST } \\
-\Delta-\text { Wind }\end{array}$ \\
\hline
\end{tabular}

Fig. 7. The evolution of generating capacity by technology in the hybrid model: (A) capacity rent, and (B) capacity level.

percent, while that of generation increases by $30-100$ percent, causing the domestic price of electricity to rise by 9-28 percent. The fact that the output of $T D$ and $O H$ are less affected than that of $G E N$ implies that the former activities' outputs are being substituted for that of the latter. $^{18}$

\subsection{General equilibrium effects of technological substitution}

The second set of results demonstrates how the change in the electricity technology portfolio interacts with the intersectoral patterns of substitution induced by carbon taxes. The effect of taxes on prices is summarized in Table 3. In the hybrid model, shown in panel A, the main effect of the tax is to increase the price of fossil fuel commodities. This is particularly true for coal whose price rises by one and a

\footnotetext{
${ }^{18}$ The alert reader will have noticed from Fig. 8 that the decline in the level of activity of GEN (measured in dollars in panel C) is far larger than that the reduction in the quantity of electricity generated by its constituent technologies (measured in $\mathrm{kWh}$ in panel A). This is an example of the problem of maintaining consistency between physical energy flows and economic quantities discussed in Section 3.3.
}

half to five times, while petroleum and natural gas prices increase by $16-70$ percent, in line with their lower carbon contents. These changes have only small impacts on the prices of mobile factors and the output of downstream industries, a modest negative influence on the price of the upstream sector crude oil and gas mining, large positive effects on the price of electricity and natural resources in the electric sector, and large negative impacts on the prices of natural resources in coal and fossil-fuel mining. ${ }^{19}$

The fossil fuel price increases induce significant reductions in the use of these inputs by producers and households, where inter-fuel substitution facilitates reductions primarily in the demand for coal. This is shown in Table 4. Panels C-E show that all sectors see declines in coal use ranging from 32 to 95 percent, while in the non-fossil-fuel sectors, demands for both petroleum and natural gas decline by between 10 and 43 percent, and electricity demand shrinks by only 3-22 percent. However, consistent with the results of the previous section, electricity's demand for oil and gas rises sharply, more than doubling the sector's use of these fuels.

Fossil-fuel price increases also have the effect of inducing substitution away from non-energy inputs, which mitigates both the inter-sectoral transmission of higher energy prices and the associated reductions in the output of non-energy sectors. As shown in panel B, reductions in output are on the order of 14-38 percent for natural gas, 15-40 percent for both crude oil and gas and refined oil, and 43-83 percent for coal. These changes translate into much smaller reductions in the output of non-energy sectors: between 6 and 17 percent in electric power, 1 and 4 percent in energyintensive industries and transportation, less than 2 percent in other manufacturing industries and agriculture, and less than 1 percent in the service and rest-of-economy sectors.

\subsection{The effects of including technology detail: a structural model comparison}

The third set of results elucidates the origins and consequences of the differences in the economy's behavior which arise from the different specifications of production in the electricity sector. The different effects of carbon taxes on prices can be seen by comparing panels A and B in Table 3. The tax has similar effects on commodity prices in both models, with the top-down model exhibiting a larger increase in the price of coal and a larger decline in the price of crude oil. The impacts on factor prices are somewhat different. The top-down model sees smaller reduction in the capital rental rate and a much smaller increase in the price of the natural resource in the electric power sector.

Table 5 illustrates the differences between the top-down and hybrid models' substitution responses to the tax. The changes in the demand for coal are similar in both models. However, the substitution possibilities within the top-down

\footnotetext{
${ }^{19}$ This last result reflects the principle that the incidence of a tax falls more heavily on immobile factors (McLure, 1971).
} 

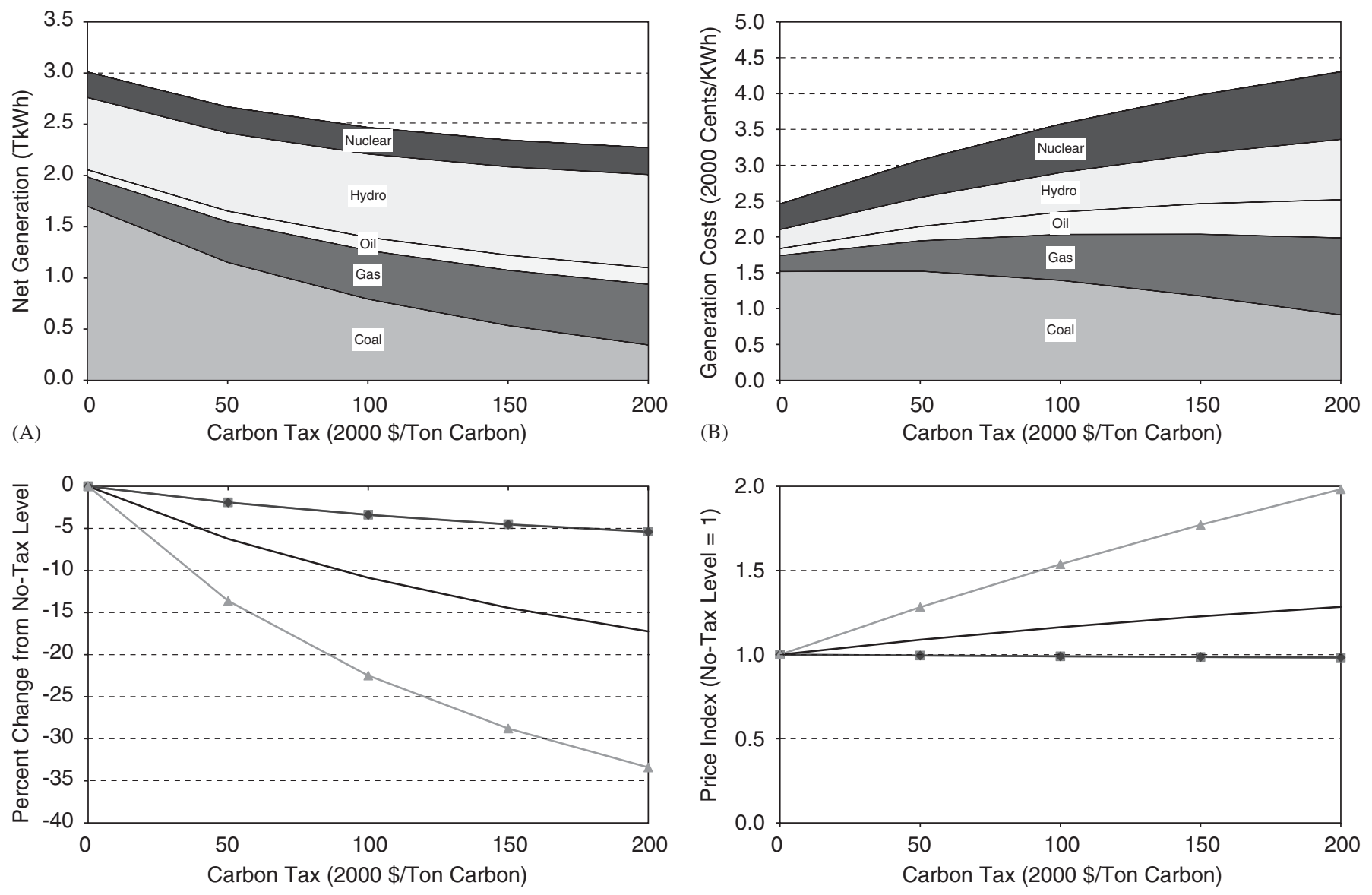

(C)

Fig. 8. The impact of carbon taxes on the hybrid model's electric power sector: (A) net generation by fue; (B) components of average cost of net generation; (C) electric sector activities; and (D) activity prices.

model's smooth production function give rise to a significant reduction in the demand for oil and natural gas by the electric power sector in panels $\mathrm{D}$ and $\mathrm{E}$. This is in contrast to the large increases in its demands for these lower-carbon alternatives in Table 4, which is the direct result of the hybrid model's inclusion of specific technologies. Panel F shows that general equilibrium effects in the markets for electricity give rise to smaller reductions in demand in non-energy sectors in the top-down model. ${ }^{20}$ The consequences, shown in panel B, are a smaller decline in aggregate electricity use coupled with a larger reduction in the aggregate demand for services. Panel A shows that, ultimately, consumption of agricultural and manufacturing output decline by a larger amount, while the consumption of services and the rest-of-economy good exhibit smaller increases. $^{21}$

\footnotetext{
${ }^{20}$ In the bottom-up model the agriculture sector's use of electricity declines slightly, whereas in the top-down model it exhibits a small increase.

${ }^{21}$ Consumption of the rest-of-economy good declines in the top-down model and increases in the bottom-up model.
}

The aggregate implications of these detailed results are summarized in Fig. 9. Panels A and B show that the two models' profiles of aggregate primary energy use in response to the carbon tax are very similar. However, in the hybrid model there is less of a decline in total primary energy use, with slightly smaller reductions in the use of fossil fuels and a much smaller expansion in primary electricity generation. The respective quantities of $\mathrm{CO}_{2}$ abatement at each tax level are shown in panel $\mathrm{C}$, which plots the marginal abatement cost (MAC) curves for the electric power sector and for the aggregate of other industries and the household sector. The loci of the equilibria of the hybrid model lie to the left those of the top-down model, indicating that the tax induces a larger quantity of abatement in the latter. The reductions in $\mathrm{CO}_{2}$ emitted by the electricity sector in the hybrid model are some 200-450 million tons smaller than that in the topdown model. The biggest differences occur at low levels of the tax.

It is also noteworthy that the difference in abatement by the remainder of the economy is small (35-65 MT), which suggests that the direct effects of technology interactions 


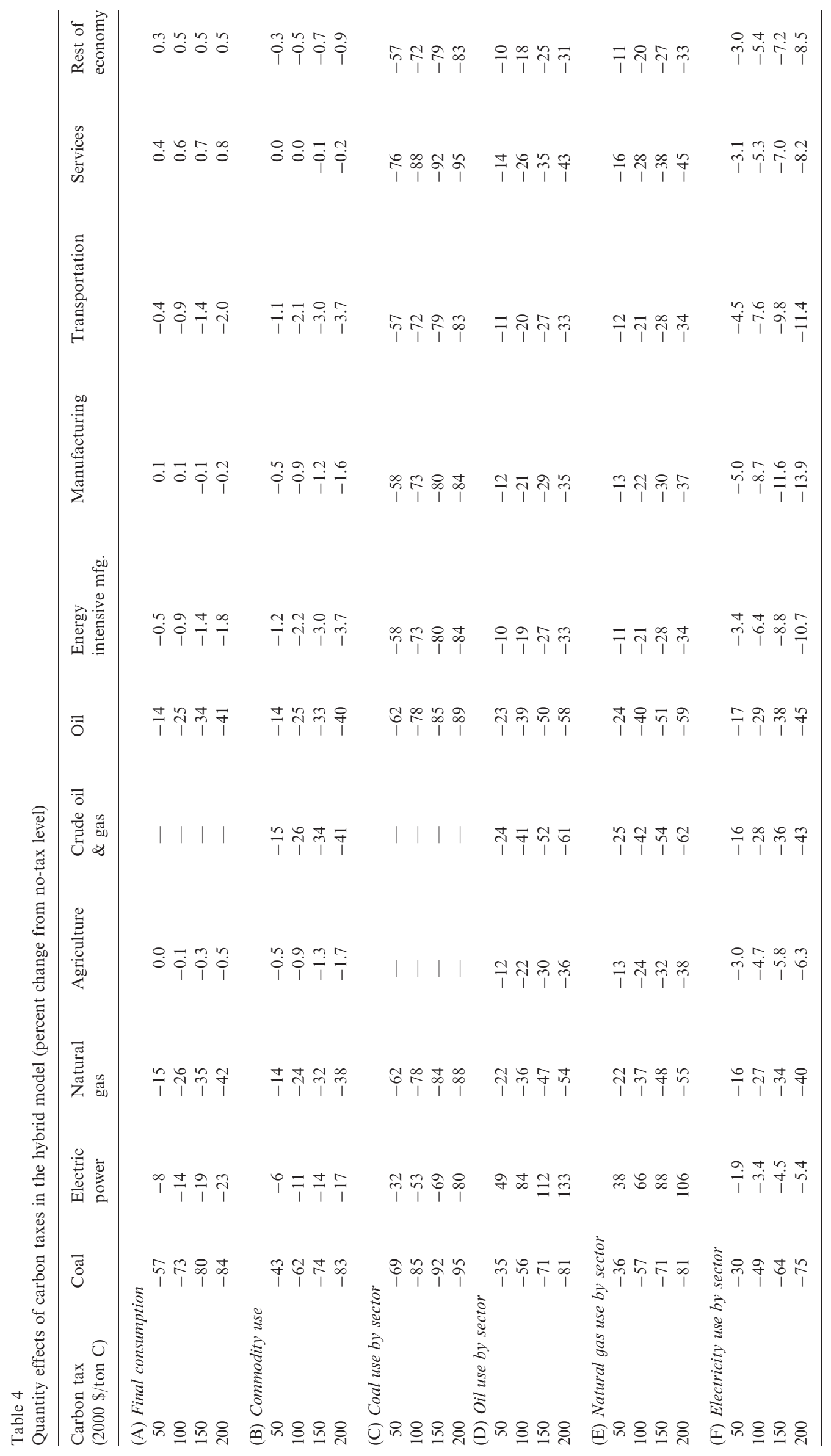




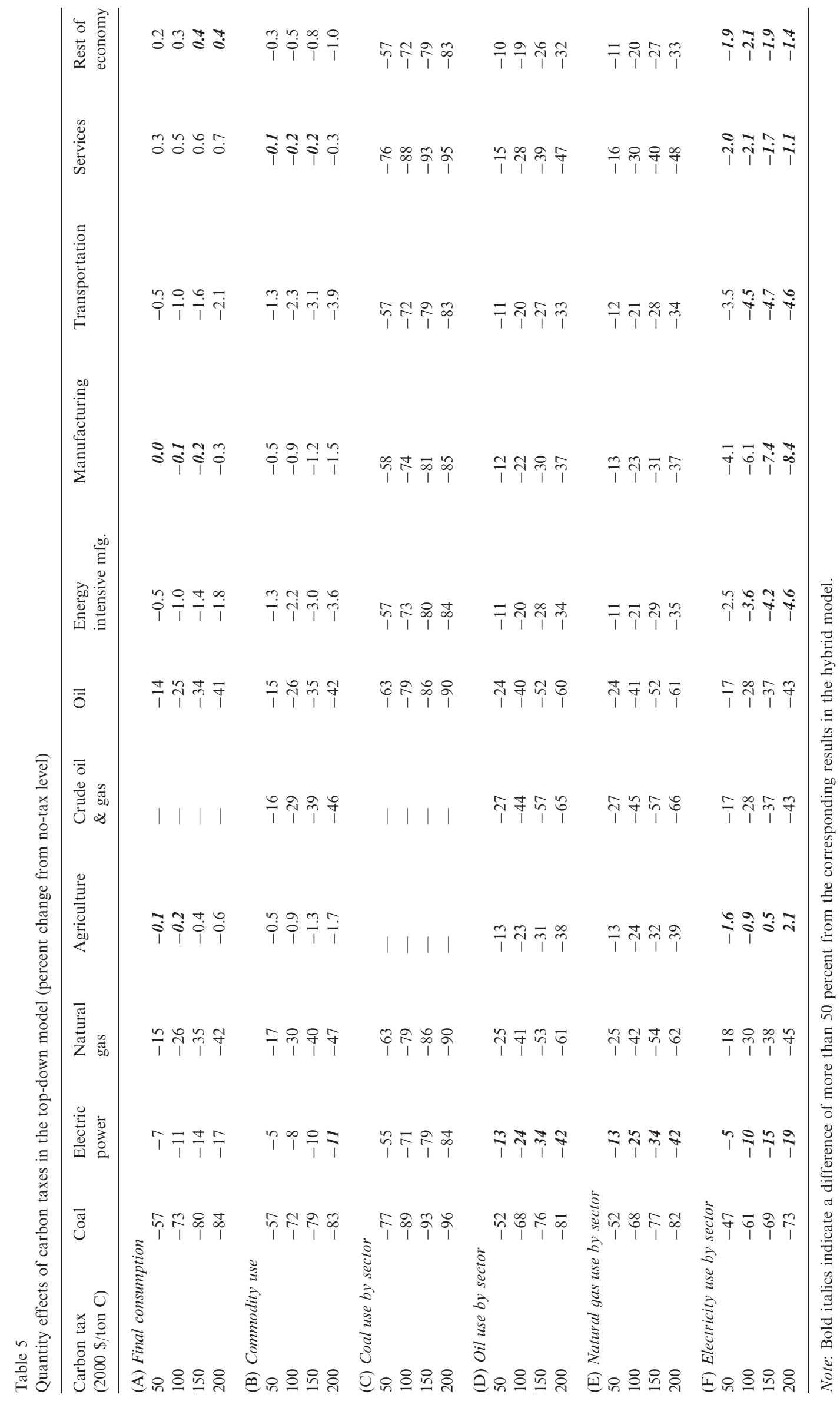



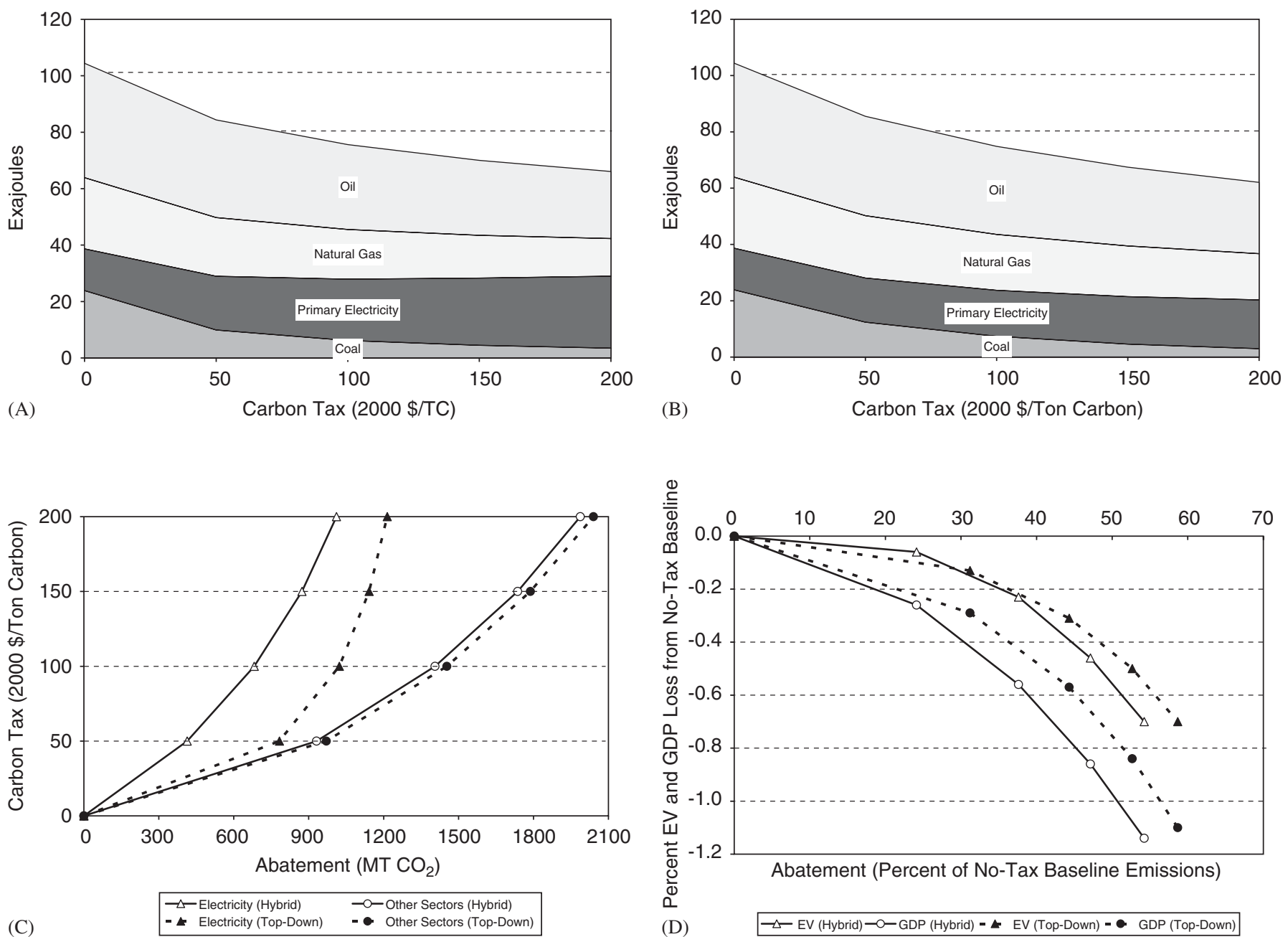

(C)

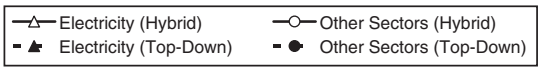

(D)

$\Delta-\mathrm{EV}$ (Hybrid) $\rightarrow$ O GDP (Hybrid) - « EV (Top-Down) - • GDP (Top-Down)

Fig. 9. Differences between the top-down and the hybrid model: energy use, $\mathrm{CO}_{2}$ abatement and macroeconomic costs: (A) primary energy use (top-down model); (B) primary energy use (hybrid model); (C) marginal abatement cost curves; and (D) GDP and welfare losses.

predominate and that general equilibrium effects have only a modest influence on aggregate abatement. This suggests that the two models' common structure and parameterization outside of the electricity sector give rise to very similar behavior there, with the result that the differences in the model simulations are attributable to their top-down and bottom-up representations of electric power production.

The consequences for the macroeconomic costs of $\mathrm{CO}_{2}$ emission limits are shown in panel D. The graph shows the difference in the aggregate responses of the two models to the tax, in terms of both the percentage abatement from counterfactual $\mathrm{CO}_{2}$ emissions and the reductions in GDP and the value of consumption (equivalent variation) precipitated by these cuts. In the top-down model, a $\$ 200 /$ ton carbon tax reduces emissions by almost 60 percent below the no-tax level, reduces GDP by 1.1 percent, and incurs a welfare loss of 0.7 percent of the total value of consumption. By comparison, in the hybrid model aggregate abatement as a percentage of baseline emissions is some 5 points less, with both GDP and equivalent variation exhibiting more elastic responses that result in larger welfare losses. But although GDP losses in the hybrid model uniformly exceed those of its top-down counterpart, for carbon taxes of less than $\$ 50 /$ ton the hybrid model generates abatement at a lower welfare cost.

The origin of these differences in model behavior can be traced back to the detailed results. Comparing the two models' final consumption vectors in panel A of Tables 4 and 5, at low levels of the tax the hybrid model makes smaller reductions in the consumption of agriculture and manufacturing output, while at high levels of the tax it experiences larger reductions in the consumption the rest-of-economy good, whose larger share of benchmark demand in Fig. 3 indicates its greater influence on equivalent variation.

From a structural standpoint, the key driver of the foregoing results is the Leontief specification of technologies in the hybrid model, which forces a complementary relationship between fuel and technology-specific capital that is in inelastic supply. By contrast, the top-down model's 
nested production structure admits inter-fuel substitutionimplicitly treating different generation technologies that use the same fuel as perfectly fungible, and, crucially, substitution between fuels and inter-sectorally mobile capital. The latter in particular enables the economy to respond more elastically to the tax, and results in lower welfare costs.

\subsection{Sensitivity analysis: the importance of capacity malleability}

The fourth set of results establishes the sensitivity of the results of the last section to the malleability of the capacities of the different generating technologies. A key issue is the possibility that top-down and bottom-up simulations may both be underestimating the macroeconomic costs of climate policy. Top-down models tend to treat capital as malleable and inter-sectorally mobile, while bottom-up models treat capacity as being in perfectly elastic supply. By comparison, the hybrid model's constraints on the reversibility of capacity in key energy-supply technologies gives rise to the kind of short-run increases in policy costs documented by Jacoby and Sue Wing (1999).

This last section explores the importance of these effects by focusing on the key role played by the elasticity of transformation between malleable and technology-specific capital. The price-responsiveness of capacity is governed the parameter $\sigma_{C A P}$, accordingly the sensitivity test involves doubling and halving the value of $\sigma_{C A P}$ relative to its benchmark figure of unity, and examining the effects on the hybrid model of different levels of the carbon tax. Table 6 summarizes the consequences for capacity rents and the levels of technology-specific capital, which follow the broad pattern in Fig. 7 with both $v_{K, \theta}^{*}$ and $p_{K, \theta}^{*}$ declining in coal generation but increasing in other technologies. ${ }^{22} \mathrm{In}$ all cases, the higher the value of $\sigma_{C A P}$ the smaller the change in the capacity rent, and the larger the change in the capacity level occasioned by a carbon tax. At the low value of $\sigma_{C A P}$ the retirement of old capacity and the addition of new capacity are both inelastic with respect to the capacity rent, at the baseline value of $\sigma_{C A P}$ retirement is elastic and addition remains inelastic, while at the high value of $\sigma_{C A P}$ both addition and retirement are elastic.

The effects of these adjustments on aggregate emissions and welfare are shown in Fig. 10. In panel A, doubling (halving) the value of $\sigma_{C A P}$ causes an outward (inward) shift of the electric sector MAC curve of as much as $50 \mathrm{MT}$ of $\mathrm{CO}_{2}$. The change in emissions associated with the retirement of coal generating capacity seen in Fig. 7 is primarily responsible for this effect, which is largest at low levels of the carbon tax but diminishes at higher tax rates. The fact that technologies' outputs of electricity are near-

\footnotetext{
${ }^{22}$ The exception is nuclear power, whose high unit cost relative to other fossil and carbon-free generation technologies results in a small decreases in capacity with high values of $\sigma_{C A P}$. The model chooses to re-allocate some of the electric sector fixed-factor from nuclear generation to other carbon-free technologies with lower unit costs of production, principally hydro.
}

perfect substitutes isolates these changes, preventing them from influencing the MAC curves of other industries in the model. The largest impacts of capacity adjustments are therefore on the quantities of fossil fuels used in electricity generation, and the abatement supplied by the electricity sector at each level of the carbon tax.

Panel B illustrates the corresponding changes in equivalent variation. The decline in abatement with smaller values of $\sigma_{C A P}$ results in larger emission fee payments by the electric sector. But the concomitant increase in the representative agent's income fails to compensate for the additional distortionary effects of the tax that result from reduced substitutability on the supply side of the economy. Doubling (halving) the value of $\sigma_{C A P}$ thus attenuates (amplifies) the welfare losses in the base case by $2-5$ percent. Although the magnitude of this impact is not dramatic, it is nonetheless sufficient to shift the hybrid model's welfare losses into the range of those of the topdown model. The fact that that these changes are solely the result of altering the value of $\sigma_{C A P}$ is testament to the importance of this parameter.

In light of these findings it is natural to ask whether making technology-specific capital fully malleable would make the top-down and the hybrid models exhibit identical responses to a carbon tax. It turns out that the answer to this question is no. Panel A shows that even with perfectly elastic capacity adjustment - which I approximate by making the elasticity of capacity transformation very large $\left(\sigma_{C A P}=10\right)$ - the hybrid model still emits more $\mathrm{CO}_{2}$ than its top-down counterpart, with variations in $\sigma_{C A P}$ accounting for 50-65 percent of the difference in the electric sector's abatement between the two models. The remainder of the abatement gap is accounted for by the differences in interfuel substitution which result from the models' dissimilar production structures. Put another way, the discretization of the hybrid model's production function is responsible for $35-50$ percent of the gap between its response and the topdown model's response to carbon taxes. Moreover, panel B indicates that the hybrid model with highly elastic capacity adjustment produces abatement at a much lower welfare cost, mainly because of the low costs of capacity retirement in coal and capacity expansion in gas. ${ }^{23}$

To verify the robustness of these findings, a final experiment was conducted to examine their sensitivity to the fungibility of technologies' output, by changing the elasticity of substitution $\sigma_{G E N}$. The results, which are shown in panels C and D of Fig. 10, indicate that the lower the substitutability of technologies' outputs, the smaller the changes in abatement and capacity induced by carbon taxes. Relative to panel A, halving the value of $\sigma_{G E N}$ reduces the quantity of the electric sector's abatement by

\footnotetext{
${ }^{23}$ When $\sigma_{C A P}=10$, both the exit of coal capacity and the addition of capacity in lower-carbon fuels occur at what would seem to be implausibly high rates. For example, a $\$ 200$ carbon tax induces a decline in steam coal generation of 70 percent and an increase in combined-cycle gas generation of 134 percent!
} 
Table 6

Sensitivity of primal and dual capacity variables to malleability assumptions $\left(\sigma_{C A P}\right)$

\begin{tabular}{|c|c|c|c|c|c|c|}
\hline & \multicolumn{2}{|c|}{$\sigma_{C A P}=1.0$} & \multicolumn{2}{|c|}{$\sigma_{C A P}=0.5$} & \multicolumn{2}{|c|}{$\sigma_{C A P}=2.0$} \\
\hline & $\$ 100 / \mathrm{TC}$ & $\$ 200 / \mathrm{TC}$ & $\$ 100 / \mathrm{TC}$ & $\$ 200 / \mathrm{TC}$ & $\$ 100 / \mathrm{TC}$ & $\$ 200 /$ TC \\
\hline \multicolumn{7}{|c|}{ (A) Capacity rent (percent change from no-tax baseline) } \\
\hline Coal ST & -41 & -74 & -54 & -89 & -31 & -58 \\
\hline Coal CC & -21 & -47 & -30 & -57 & -16 & -37 \\
\hline Gas IC & 115 & 167 & 131 & 237 & 74 & 89 \\
\hline Gas GT & 121 & 174 & 141 & 255 & 76 & 89 \\
\hline Gas ST & 110 & 162 & 124 & 225 & 73 & 89 \\
\hline Gas CT & 107 & 159 & 120 & 218 & 72 & 90 \\
\hline Gas CC & 87 & 133 & 92 & 169 & 64 & 85 \\
\hline Oil IC & 133 & 196 & 156 & 282 & 84 & 104 \\
\hline Oil GT & 142 & 205 & 170 & 306 & 86 & 103 \\
\hline Oil ST & 133 & 196 & 155 & 280 & 84 & 104 \\
\hline Oil CT & 135 & 198 & 159 & 287 & 85 & 104 \\
\hline Oil CC & 113 & 168 & 127 & 229 & 76 & 96 \\
\hline Hydro & 46 & 64 & 71 & 95 & 30 & 41 \\
\hline Nuclear & 32 & 33 & 63 & 67 & 15 & 15 \\
\hline Wind & 41 & 55 & 64 & 83 & 26 & 35 \\
\hline Solar & 36 & 48 & 55 & 72 & 23 & 31 \\
\hline Biomass & 40 & 53 & 65 & 83 & 25 & 33 \\
\hline Geothermal & 45 & 61 & 71 & 93 & 28 & 38 \\
\hline \multicolumn{7}{|c|}{ (B) Capacity level (percent change from no-tax baseline) } \\
\hline Coal ST & -53 & -80 & -43 & -71 & -64 & -87 \\
\hline Coal CC & -38 & -59 & -30 & -44 & -47 & -71 \\
\hline Gas IC & 69 & 110 & 27 & 57 & 126 & 160 \\
\hline Gas GT & 74 & 115 & 30 & 61 & 130 & 159 \\
\hline Gas ST & 66 & 106 & 25 & 55 & 123 & 160 \\
\hline Gas CT & 63 & 104 & 24 & 53 & 121 & 161 \\
\hline Gas CC & 47 & 84 & 16 & 41 & 100 & 150 \\
\hline Oil IC & 84 & 133 & 34 & 67 & 153 & 202 \\
\hline Oil GT & 91 & 141 & 37 & 73 & 159 & 200 \\
\hline Oil ST & 84 & 133 & 33 & 67 & 153 & 202 \\
\hline Oil CT & 85 & 135 & 34 & 68 & 154 & 201 \\
\hline Oil CC & 68 & 111 & 26 & 55 & 131 & 178 \\
\hline Hydro & 15 & 29 & 9 & 20 & 26 & 45 \\
\hline Nuclear & 4 & 5 & 7 & 11 & -2 & -5 \\
\hline Wind & 11 & 22 & 7 & 16 & 18 & 33 \\
\hline Solar & 7 & 17 & 4 & 12 & 13 & 26 \\
\hline Biomass & 11 & 21 & 7 & 16 & 16 & 28 \\
\hline Geothermal & 15 & 27 & 9 & 19 & 23 & 39 \\
\hline
\end{tabular}

50-100 MT and attenuates the effect of $\sigma_{C A P}$ on the position of its MAC curve. ${ }^{24}$ When $\sigma_{G E N}=5$, variations in $\sigma_{C A P}$ only account for 25-30 percent of the gap between the quantities of abatement by electric power in the two models. The implication is that the greater the differentiation of technologies in terms of their ability to supply different categories of load, the less important capacity malleability becomes.

\footnotetext{
${ }^{24}$ When $\sigma_{G E N}=10$, varying $\sigma_{C A P}$ from 0.5 to 2 changes the electricity sector's abatement response to a $\$ 100 /$ ton tax by 198 MT (from 580 to $778 \mathrm{MT}$ ), and that from a $\$ 200 /$ ton tax by $119 \mathrm{MT}$ (from 942 to $1061 \mathrm{MT}$ ). When $\sigma_{G E N}=5$, the same variation in $\sigma_{C A P}$ induces changes in abatement for the corresponding tax levels of $131 \mathrm{MT}$ (from 547 to $678 \mathrm{MT}$ ) and $93 \mathrm{MT}$ (from 862 to $955 \mathrm{MT}$ ), respectively. The shift in the MAC curve for the remainder of the economy is negligible.
}

However, panel B shows that diminished inter-technology substitution does not cause an appreciable shift in the positions of the loci of welfare losses. Thus, although discretizing the top-down model's smooth production function for electric power reduces the aggregate substitutability of the model's supply side, which decreases the quantity of aggregate abatement, the result is only a small effect on the aggregate cost of reducing emissions. The implication is that response of the latter to the carbon tax is dominated by the elasticity of capacity adjustment, which is unsurprising, since the lower the value of $\sigma_{C A P}$ the more the endowments of technology-specific capacity take on the character of fixed factors. This finding confirms the crucial role played by the short-run capacity malleability in determining the macroeconomic costs of climate policies. 


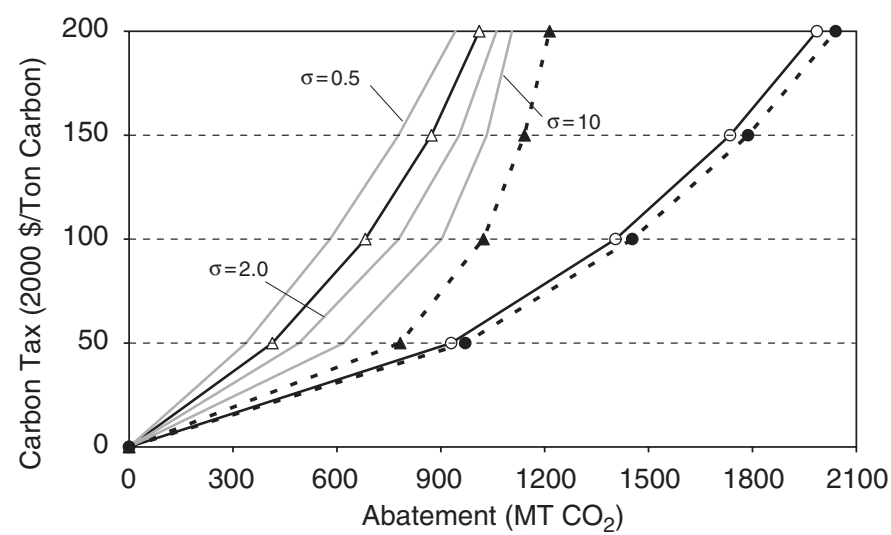

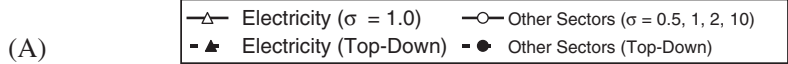

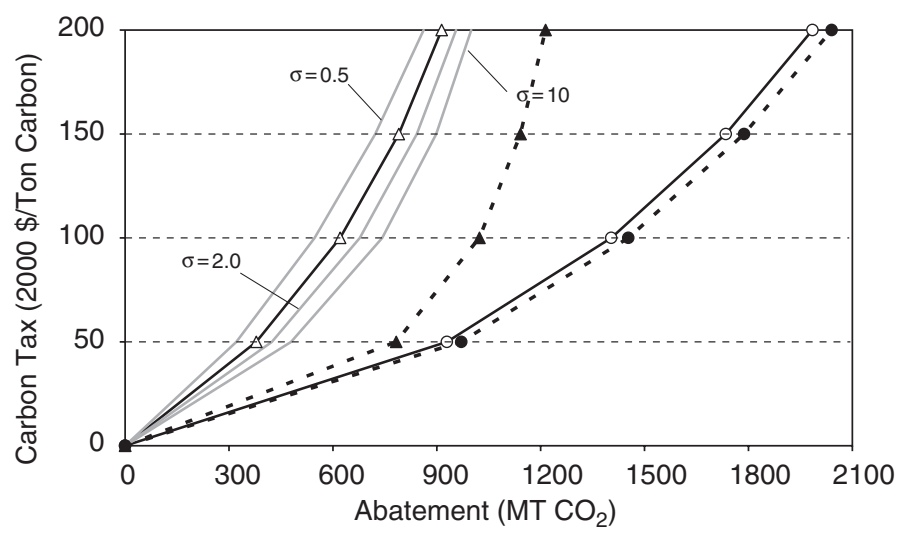

(C)

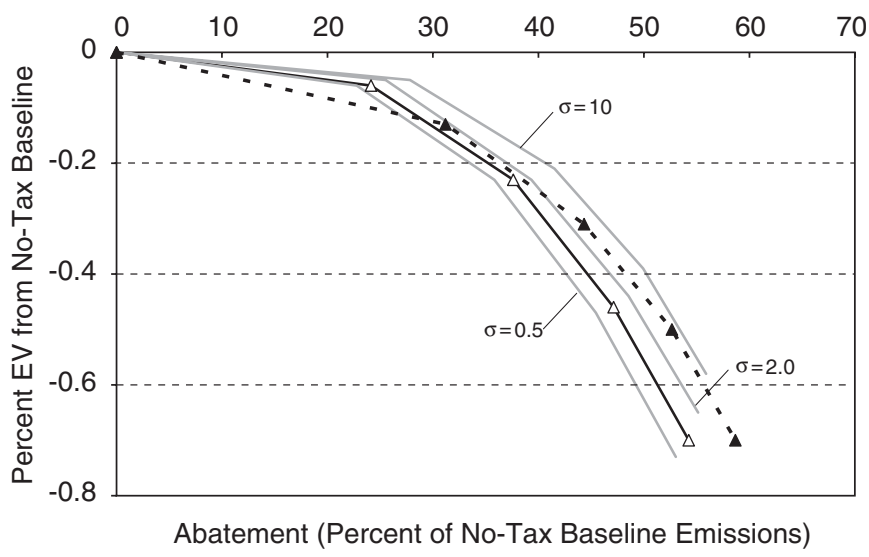

(B)

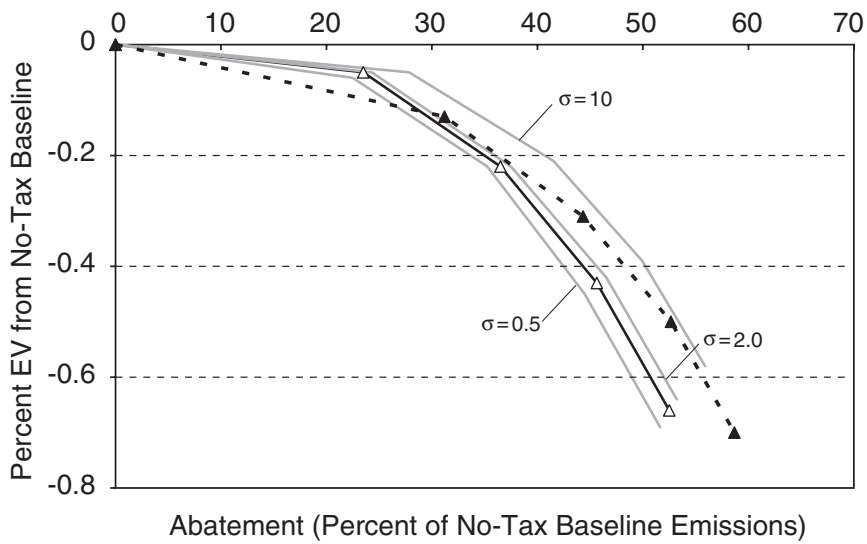

(D)

Fig. 10. Sensitivity of the hybrid model to values of $\sigma_{C A P}$ : (A) marginal abatement cost curves $\left(\sigma_{G E N}=10\right)$; (B) welfare losses $\left(\sigma_{G E N}=10\right)$; $(\mathrm{C})$ marginal abatement cost curves $\left(\sigma_{G E N}=5\right)$; and (D) welfare losses $\left(\sigma_{G E N}=5\right)$.

\section{Conclusions}

It is predicted that the bulk of the reduction in the US economy's $\mathrm{CO}_{2}$ emissions in response to carbon taxes will come from electric power. This paper has characterized the effects of carbon taxes on electric generation technologies and the US electricity sector, comparing the general equilibrium effects of carbon taxes in two CGE models that differ only in terms of their representations of the production of electric power.

The results show that, for a given degree of optimism regarding the substitution possibilities in electricity production, the welfare costs of emission taxes in a hybrid model with a technologically rich description of the electric power sector generally exceed those in a top-down model in which the sector is represented by a smooth production function. Nevertheless, for modest abatement of 10-20 percent from baseline emission levels, and corresponding carbon taxes of less than $\$ 50$ per ton, welfare losses still appear to be smaller in the hybrid model than in the top- down model. Thus the main findings of the paper are most relevant for emission reduction policies that are significantly more stringent than those currently under consideration (e.g., NCEP, 2004).

This behavior was shown to emanate from the discretization of the hybrid model's electric sector production function on one hand, which reduces the aggregate input substitutability on the supply side of the economy, and the imperfect malleability of technology-specific capital on the other hand, which limits the adjustment of generating capacity in the short-run. While macroeconomic costs are affected by the substitutability of electricity generation technologies in their ability to supply different categories of load, it appears that the crucial factor is the ease with which existing capacity in relatively high-cost technologies may be retired or with which new capacity in relatively lowcost technologies can be added in the short run.

The results are qualitatively similar to those of Jacoby and Sue Wing (1999), using a CGE model with a very different structure and database. However, this corrobor- 
ating evidence also highlights just how little is understood about the determinants of capital malleability, particularly as it pertains to short-run irreversibility and capacity adjustment in large-scale energy supply technologies, and how the adjustment process should be represented in CGE models. The all-important elasticity of capacity adjustment, the device used to parameterize the ease of retrofit or retirement of technologies in the short run, is thus little more than a measure of our ignorance.

In this respect the paper provokes several questions. From an empirical perspective, what are the determinants of capacity retirement and retrofit decisions in the electric power sector, and how responsive are these to energy price shocks? Given that carbon taxes are likely to be announced many years in advance of their entry into force, how might these responses differ in an inter-temporal setting where producers are able to anticipate price increases? Ultimately, these elements need to be combined in a framework which can be used to estimate the elasticity of capacity transformation. From a modeling perspective, how does the present method of simulating capacity adjustment compare with other ways of representing such short-run frictions such as the "vintaging" approach of Jacoby and Sue Wing, and how might these practicable but ad hoc approaches be brought closer into line with the theoretically correct but more complicated Hayashi-Summers adjustment-cost framework? And finally, what do these different approaches imply for the dynamics of penetration and exit of energy supply technologies, and ultimately the long-run costs of climate change mitigation?

Hopefully, the contribution of this paper will be to encourage more researchers to explore these vitally important issues.

\section{References}

Boehringer, C., 1998. The synthesis of bottom-up and top-down in energy policy modeling. Energy Economics 20, 233-248.

Boehringer, C., Hoffmann, T., Loeschel, A., 2003. Dismantling nuclear power in Europe: macroeconomic and environmental impacts. ZEW Discussion Paper No. 03-15, University of Mannheim.

Bovenberg, A.L., Goulder, L.H., 1996. Costs of environmentally motivated taxes in the Presence of other taxes: general equilibrium analyses. American Economic Review 86, 985-1006.

Brooke, A., Kendrick, D., Meeraus, A., Raman, R., 1998. GAMS: A User's Guide. GAMS Development Corp., Washington, DC.

Dirkse, S.P., Ferris, M.C., 1995. The PATH solver: a non-monotone stabilization scheme for mixed complementarity problems. Optimization Methods and Software 5, 123-156.

DOE/EIA, 2003a. Assumptions to the annual energy outlook. DOE/EIA0554(2003), Washington, DC.

DOE/EIA, 2003b. Electric power annual 2002. DOE/EIA-0348(2002), Washington, DC.

DOE/EIA, 2003c. Emissions of greenhouse gases in the United States 2002. DOE/EIA-0573(2002), Washington, DC.

Frei, C.W., Haldi, P.-A., Sarlos, G., 2003. Dynamic formulation of a topdown and bottom-up merging energy policy model. Energy Policy 31, 1017-1031.

Fullerton, D., 1983. Transition losses of partially mobile industry-specific capital. Quarterly Journal of Economics 98, 107-125.
Goolsbee, A., 1993. Fuel costs and the retirement of capital goods, Working Paper No. WP-93016. MIT Center for Energy and Environmental Policy Research.

Goolsbee, A., 1998. The business cycle, financial performance, and the retirement of capital goods. Review of Economic Dynamics 1, 474-496.

Goolsbee, A., Gross, D.B., 1997. Estimating adjustment costs with data on heterogeneous capital goods. NBER Working Paper No. 6342.

Grubb, M., Edmonds, J., ten Brink, P., Morrison, M., 1993. The costs of limiting fossil-fuel $\mathrm{CO}_{2}$ emissions: a survey and analysis. Annual Review of Energy and the Environment 18, 397-478.

Grubler, A., Nakicenovic, N., Victor, D.G., 1999. Modeling technical change: implications for the global environment. Annual Review of Energy and the Environment 24, 545-569.

Harrison, G.W., Tarr, D., Rutherford, T.F., 1997. Quantifying the Uruguay Round. Economic Journal 107, 1405-1430.

IPCC, 1995. Climate change 1995: Economic and Social Dimensions of Climate Change. Cambridge University Press, Cambridge.

IPCC, 2001. Climate Change 2001: Mitigation. Cambridge University Press, Cambridge.

Jacoby, H.D., Sue Wing, I., 1999. Adjustment time, capital malleability, and policy cost. Energy Journal 73-92 (special issue: The Costs of the Kyoto Protocol: A Multi-Model Evaluation).

Kumbaroglu, G., Madlener, R., 2003. Energy and climate policy analysis with the hybrid bottom-up computable general equilibrium model SCREEN: the case of the Swiss $\mathrm{CO}_{2}$ Act. Annals of Operations Research 121, 181-203.

Loulou, R., Goldstein, G., Noble, K., 2004. Documentation for the MARKAL family of models. Energy Technology Systems Analysis Programme, OECD/IEA.

Manne, A.S., Richels, R.G., Mendelsohn, R., 1995. A model for evaluating regional and global effects of GHG reduction policies. Energy Policy 23, 17-34.

Mathiesen, L., 1985a. Computational experience in solving equilibrium models by a sequence of linear complementarity problems. Operations Research 33, 1225-1250.

Mathiesen, L., 1985b. Computation of economic equilibria by a sequence of linear complementarity problems. Mathematical Programming Study 23, 144-162.

McFarland, J.R., Reilly, J.M., Herzog, H.J., 2004. Representing energy technologies in top-down economic models using bottom-up information. Energy Economics 26, 685-707.

McLure, C.E., 1971. The theory of tax incidence with imperfect factor mobility. Finanzarchiv 30, 432-453.

National Academy of Sciences (NAS), 1991. Policy Implications of Greenhouse Warming. National Academies Press, Washington, DC.

National Commission on Energy Policy (NCEP), 2004. Ending the Energy Stalemate: A Bipartisan Strategy to Meet America's Energy Challenges. National Commission on Energy Policy, Washington, DC.

Nordhaus, W.D., Boyer, J., 1999. Warming the World: Models of Global Warming. MIT Press, Cambridge, MA.

Paltsev, S., Reilly, J. M., Jacoby, H. D., Eckaus, R.S., McFarland, J., Sarofim, M., Asadoorian, M., Babiker, M., 2005. The MIT Emissions Prediction and Policy Analysis (EPPA) Model: Version 4, MIT Joint Program on the Science and Policy of Global Change Report No. 125.

Rutherford, T.F., 1987. Implementational issues and computational performance solving applied general equilibrium models with SLCP. Cowles Foundation Discussion Paper No. 837, Yale University.

Rutherford, T.F., 1999. Applied general equilibrium modeling with MPSGE as a GAMS subsystem: an overview of the modeling framework and syntax. Computational Economics 14, 1-46.

Scarf, H., 1973. The Computation of Economic Equilibria. Yale University Press, New Haven.

Sue Wing, I., 2001. Induced technical change in computable general equilibrium models for climate policy analysis. Unpublished Ph.D. Dissertation, Massachusetts Institute of Technology.

Sue Wing, I., 2004a. Computable general equilibrium models and their use in economy-wide policy analysis: everything you ever wanted to know 
(but were afraid to ask). Technical Note No. 6, MIT Joint Program on the Science and Policy of Global Change, Cambridge, MA.

Sue Wing, I., forthcoming. The synthesis of bottom-up and top-down approaches to climate policy modeling: electric power technology detail in a social accounting framework. Energy Economics.

Vögele, S., Hoffmann, T., Markewitz, P., 2004. Fuel substitution options in the electricity sector: the dependency on capital malleability. Paper presented at the International Conference on Input-Output and General Equilibrium: Data, Modeling, and Policy Analysis, Brussels, September $2-4$.

Wilson, D., Swisher, J., 1993. Exploring the gap: top-down versus bottomup analyses of the cost of mitigating global warming. Energy Policy 21, 249-263. 